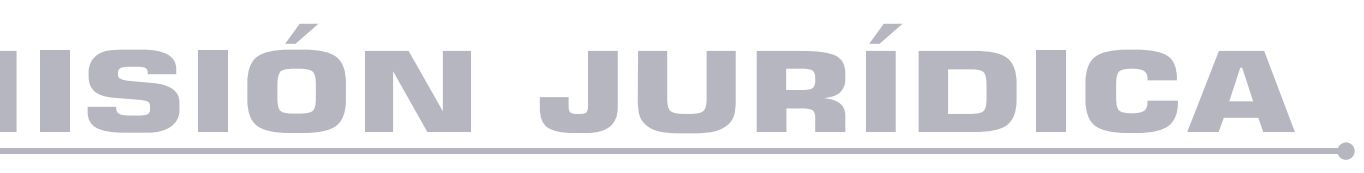

\title{
El régimen de los cementerios públicos: tras la dicotomía entre lo público y lo privado
}

The regime of public cemeteries: after the dichotomy between the public and private sectors

Autor: MsC. Erick Ortega García

DOl: https://doi.org/10.25058/1794600X.1045

\footnotetext{
Ś MISIÓN JURÍDICA A
} 


\title{
EL RÉGIMEN DE LOS CEMENTERIOS PÚBLICOS: TRAS LA DICOTOMÍA ENTRE LO PÚBLICO Y LO PRIVADO*
}

\author{
The regime of public cemeteries: after the dichotomy \\ between the public and private sectors \\ 0 regime dos cemitérios públicos: após a dicotomia \\ entre público e privado
}

\section{MsC. Erick Ortega García ${ }^{a}$}

erick@oc.dpvhab.cu

Fecha de recepción: 20 de junio de 2019

Fecha de revisión: 03 de julio de 2019

Fecha de aceptación: 03 de septiembre de 2019

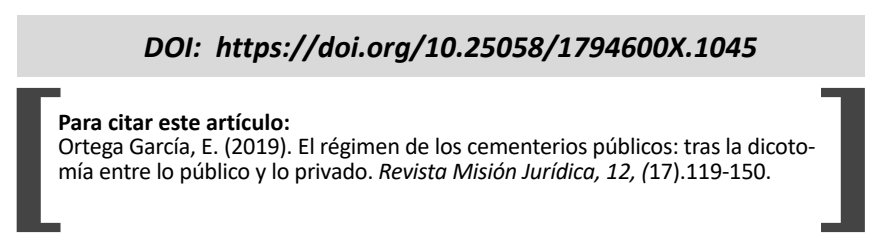

\section{RESUMEN}

Sobre todo cementerio, tanto público como privado, concurren potestades públicas, y potestades o derechos de los sujetos particulares que son usuarios del servicio de cementerio. Parte de sus contradicciones normativas, que generan lagunas en los ordenamientos, vienen dadas desde la evolución histórica de los camposantos. Su nacimiento junto al hombre disponiendo sitios para inhumar los restos humanos, produjo un retardo en su evaluación como sujeto de derechos.

\footnotetext{
* Artículo de reflexión que presenta los resultados parciales de un proyecto de investigación doctoral en curso, adscripto al Programa de Formación Doctoral de la Universidad de Oriente, Cuba, a defender en febrero de 2020, asociado al Proyecto: Fortalecimiento de las capacidades de los actores locales para el logro de la inclusión de grupos vulnerables al desarrollo local, perteneciente al Centro de Estudios Sociales Cubanos y Caribeños (CESCA) "José Antonio Portuondo" de la Universidad de Oriente, al Proyecto de la Facultad de Derecho de la Universidad de Oriente: Patrimonio y derechos culturales desde las Ciencias Jurídicas y la Responsabilidad Social, aprobado por la dirección del Programa Nacional Sociedad Cubana, y al Proyecto Asociado a Programa propio de la disciplina: La constitución cubana y la actualización del modelo económico social.

a. Licenciado en Derecho por la Facultad de Derecho de la Universidad de Camagüey, Cuba, en 2002. Especialista en Derecho Civil y Patrimonial de Familia por la Facultad de Derecho de la Universidad de Camagüey, Cuba en 2009. Máster en Derecho Constitucional y Administrativo por la Facultad de Derecho de la Universidad de Oriente, Cuba en 2016. A partir de entonces recibió diferentes estudios posgraduados como Curso de Derechos Humanos y Derecho Internacional Humanitario. Universidad de Oriente, Santiago de Cuba, Octubre/2004. Curso: "Tendencias actuales del Derecho Empresarial", Universidad Iberoamericana de Puebla, México, Septiembre/2009. Seminario Internacional “Derecho Internacional Público", Universidad Rey Juan Carlos, Madrid, España. Junio/2013. Curso: "Participación, Desarrollo Local y Soberanía Alimentaria". Universidad de Oriente, Santiago de Cuba, Noviembre de 2013. Curso: "Redacción científica". Universidad de Las Tunas, Marzo/2014. Se desempeña en la actualidad como Jefe de Departamento Jurídico en la Dirección Provincial de la Vivienda de La Habana, Cuba.Es Profesor Asistente. Es miembro de la Unión Nacional de Juristas de Cuba, y de los Capítulos de Derecho Civil y Familia y Derecho Notarial en la Sede Provincial de La Habana. Han impartido Cursos Postgrados en materia Inmobiliaria y de Familia. Han participado en Eventos Internacionales, desarrollando una amplia producción científica de investigaciones que fueron presentadas en diversos eventos provinciales, nacionales e internacionales.
} 
Todo ello ha generado que una de las principales dificultades a las que se enfrentan los operadores jurídicos al tratar las cuestiones que afectan a los cementerios, es la complejidad y dispersión del régimen jurídico de sus fuentes. La vaguedad en su tratamiento, genera incertidumbre en el actuar de la administración y usuarios. Ello conlleva a que surjan arbitrariedades contra los derechos de los administrados, y generan responsabilidad de la Administración por la ejecución de actos absoluta o relativamente nulos.

A partir de los retos que la materia impone, se presenta una caracterización del régimen jurídico de los cementerios públicos. Para ello se aborda un estudio comparado de la regulación normativa de los derechos y bienes que lo integran. Como resultado, se ofrece un diagnóstico del régimen jurídico actual de los cementerios públicos, contentivo de su análisis teórico-doctrinal, que permita enmarcarlos dentro de los bienes del patrimonio público, a fin de garantizar su protección jurídica y publicidad registral en la actuación administrativa encaminada al logro de su resguardo legal.

\section{PALABRAS CLAVES}

Cementerios, dominio público, Administración pública.

\section{ABSTRACT}

On every cemetery, public or private, public competencies and competencies or rights of the particular clients that are users of the cemetery service converge. Their normative contradictions generate gaps in the classifications, this derives from the cemeteries' historical evolution . Their creation that arose with man's need to prepare places to bury human remains, produced a delay in their recognition as subjects of rights.

All these has generated one of the main difficulties that juridical operators face while treating the problems that affect cemeteries, which is the complexity and dispersion of the cemeteries juridical regime, and of its sources. The imprecision in its treatment results in uncertainty in the procedures the administration and users should follow. This leads to arbitrariness against the rights of clients, and for the Administration generates responsibility for the execution of absolute or relatively null acts.
Starting from the challenges that the matter imposes, a characterization of the juridical regime of public cemeteries is presented. For this, a comparative study of the normative regulation of the rights and goods that integrate it is outlined. As a result, a diagnosis of the current juridical regime of public cemeteries is offered, based on their theoretical-doctrinal analysis that allows for them to be framed as goods of public patrimony, in order to guarantee their legal security and publicity in the administrative act and towards the achievement of their legal protection.

\section{KEY WORDS}

Cemeteries, public domain, Public Administration.

\section{RESUMO}

Em todo cemitério, público e privado, existem poderes públicos e direitos ou direitos de indivíduos particulares usuários do serviço do cemitério. Parte de suas contradições normativas, que geram lacunas nas ordenanças, provém da evolução histórica sua. Seu nascimento com o homem, fornecendo lugares para desumanizar restos humanos, causou um atraso em sua avaliação como sujeito de direitos.

Tudo isso gerou que uma das principais dificuldades que os operadores legais enfrentam ao lidar com questões que afetam os cemitérios é a complexidade e dispersão do regime jurídico dos cemitérios, a partir de fontes. A imprecisão em seu tratamento gera incerteza nas ações da administração e dos usuários. Isso leva ao surgimento de arbitrariedade contra os direitos dos administradores e gera responsabilidade da Administração pela execução de atos absolutos ou relativamente nulos.

Com base nos desafios que o assunto impõe, é apresentada uma caracterização do regime jurídico dos cemitérios públicos. Para isso, é abordado um estudo comparativo da regulamentação normativa dos direitos e ativos que a compõem. Como resultado, é oferecido um diagnóstico do atual regime jurídico dos cemitérios públicos, conteúdo de sua análise teórico-doutrinária, que permite enquadrá-los no patrimônio do patrimônio público, a fim de garantir sua proteção jurídica e registro na publicidade da ação administrativa à consecução de sua proteção legal. 


\section{PALAVRAS-CHAVE} pública

Cemitérios, domínio público, administração

\section{INTRODUCCIÓN}

La muerte, como proceso natural, trae consigo la desaparición física de la persona, lo que no implica el olvido por sus seres queridos; existen para ello los cementerios, constituidos como lugar de eterno recuerdo. Protectores de la higiene y la salubridad pública, sus espacios posibilitan el acceso a significados, valores, ideologías, devociones, aficiones y relaciones sociales. Presentes en todas las épocas, han sido escenario de los más diversos estilos arquitectónicos funerarios. Su estabilidad sobre tiempos y lugares biográficos, lo convierten en museos al aire libre, e imprescindibles fuentes históricas. Inscritos en la lógica de lo local y el plano identitario de la cultura, su estudio no puede pasar inadvertido ni para el legislador, ni para la doctrina científica.

El término cementerio proviene del griego koimeterion, de koimao, que significa dormitorio o lugar de descanso; y del latín coementerium, que deriva a su vez de cinisterium, cuyas raíces provienen de los términos cinos: dulce y tenor: mansión ${ }^{1}$. Por tanto, en sus primeras acepciones, siempre conllevó la noción de reposo a la espera de la resurrección. Desde la Ley de Partidas, el concepto de cementerio no ha cambiado. La Partida Primera, Título XIII, Ley 4ta, lo definió como "logar donde sotlerran los muertoe e se tornan los cuerpos tlellos ceniza"2.

Se conoce por cementerio o camposanto, al lugar donde se depositan los restos mortales o cadáveres de los difuntos (inhumación); cuyas formalidades y solemnidades van de la mano del desarrollo y costumbres culturales de cada pueblo en particular. En correspondencia a esos modos, los cuerpos pueden introducirse en ataúdes, féretros o sarcófagos, o simplemente envolverse

1. En Italia se acuña el término "camposanto", dado al recubrimiento con tierra traída de los lugares santos de Jerusalén, a Pisa, cuando se ordenó la clausura del cementerio intramuro, lo que constata la influencia del Derecho romano que ubicó a las sepulturas en las res divini iuris, y dentro de éstas como res religiosa. El vocablo alemán friedhafs (campo de paz o lugar de sueño) coincide con ambas acepciones. ARANGLO RUIZ, V. (1952) Instituciones de Derecho romano, traducido por José M. CARAMÉS PERRo, Buenos Aires: Depalma, p.189.

2. REY Don Alfonso X El SABIo (1807) Siete Partidas, Madrid: Imprenta Real, pp. 22-23. en telas, para ser depositados bajo tierra o en nichos, criptas u otro tipo de sepulturas ${ }^{3}$. Más allá de la necesidad de colocar en algún lugar el cuerpo de los difuntos, los camposantos resultan lugares venerables.

Los hallazgos arqueológicos dan cuenta de la existencia de sepulcros de por lo menos 40.000 años de antigüedad. Ha sido la preocupación del hombre por enterrar a sus muertos, la nota distintiva de la civilización. Ello demuestra que el rito de sepultar data de cuando se formaron las primeras organizaciones sociales, ligado a creencias religiosas o a prácticas mágicas. No obstante, el cementerio tal como hoy se conoce, tiene un origen relativamente reciente. En la antigüedad, los enterramientos se efectuaban en las viviendas, catacumbas y mastabas. Ya en el siglo V y hasta finales del siglo XVIII, las iglesias eran los únicos espacios para los muertos. En áreas de terrenos aledaños a ellas y en sus propios interiores, se inhumaban de forma anónima, salvo los ilustres personajes de la época.

Con el advenimiento del siglo XVIII, debido a las ideas higienistas y los avances en las ciencias, comenzó a denunciarse la situación insalubre de las iglesias. Simultáneamente, toda Europa comenzó el denominado "exilio de los muertos". Se proyectan así, cementerios extramuros con premisas totalmente distintas a las anteriores formas de enterramientos. A medida que comienzan a proliferarse, se va haciendo necesario reglar su funcionamiento. La normativa general que de su regulación nace, conjuga principios de derecho público y privado. De acuerdo a su naturaleza integra elementos administrativos, urbanísticos, contractuales e inmobiliarios ${ }^{4}$.

En este contexto, es la Administración Pública quien ha asumido el encargo de su reglamentación general. Ello se debe a que, si bien el patrimonio administrativo se integra tanto por bienes de

3. El término cementerio se define como el terreno descubierto destinado al entierro de cadáveres de los fieles, con la intervención de la autoridad del superior del eclesiástico y la consagración solemne del lugar. ESCRICHE, J. (1863) Diccionario Razonado de Jurisprudencia y Legislación, Paris: Librería de Rosa y Bouret, p. 431.

4. ARIÉS, Ph. (1984) El hombre ante la muerte, Madrid: Taurus Ediciones, pp. 408-413. 
dominio público ${ }^{5}$ como por bienes patrimoniales ${ }^{6}$, existe consenso en la doctrina internacional ${ }^{7}$ al reconocer a la necrópolis dentro de los bienes del patrimonio público. Sin embargo, esta circunstancia colisiona las relaciones que se suscitan en los diferentes ámbitos del Derecho. Así se evidencian tres grupos, las que se propician entre el municipio y el particular (derecho público), entre el particular y la sepultura (relación de derecho administrativo), y las generadas entre los particulares (derecho privado) ${ }^{8}$.

\section{METODOLOGÍA}

Partiendo de estos elementos consideramos necesaria una investigación desde el punto de vista doctrinal a fin de caracterizar el régimen de los cementerios públicos Para ello se aborda un estudio comparado de la regulación normativa de los derechos y bienes que lo integran. Con este fin, se utilizaron los métodos histórico-lógico, que permitió enfocar el objeto de estudio, el régimen jurídico de los cementerios públicos, en un decurso evolutivo, destacando los aspectos generales de su desarrollo, las tendencias de su progreso, las etapas de su desenvolvimiento, sus conexiones fundamentales y causales; el

5. El criterio determinante de los bienes demaniales es su afectación a un uso general o servicio público. Debe existir una relación inmediata entre el bien afectado y el uso o servicio público, y encontrarse protegidos por un régimen regulatorio exorbitante. HAURIOU, M. (1927) Précis de droit administratif, Paris: Recueil Sirey, pp. 162-188. MAYER, O. (1951) El derecho administrativo alemán Tomo III Parte Especial El Derecho Público de las cosas, Buenos Aires: Depalma, p. 121. BALLESTEROS, A. (1990) Manual de Bienes de las Entidades Locales, Madrid Ministerio para las Administraciones Públicas, pp. 23-26.

6. Su definición es negativa y residual, al incluir a todos los que, siendo de titularidad de la Administración Pública, no tienen el carácter de demaniales. Susceptibles de resultar fuente de recursos, también son objeto de una afectación indirecta o mediata al cumplimiento de fines de interés general. Por ello se rigen por las normas de Derecho privado, en defecto de legislación específica. GARCÍA DE ENTERRÍA, E. y FERNÁNDEZ, T. R. (2000) Curso de Derecho Administrativo, Madrid: Civitas, pp. 93-112. PARADA, J. R. (1988) Derecho Administrativo (Bienes públicos y urbanismo), Madrid: Marcial Pons, p. 164. BALLESTERos, Manual de Bienes de las Entidades...cit., pp. 28-29.

7. SÁNCHEZ Morón, M. (1997) Los Bienes Públicos, Madrid: Tecnos, S.A, p. 37. HERNÁNDEZ, R. (2008) Situación Jurídica de los Cementerios Públicos, recuperado de: http://sitios.poderjudicial go.cr. (Consultado: 5/12/2014). PÉREZ GÁLVEZ, J. F. (1997) El sistema funerario en el Derecho español, Pamplona: Aranzadi, pp. 335 y ss.

8. En los cementerios concurre una doble condición: tienen una significación religiosa y, al mismo tiempo, poseen una relevancia jurídica-pública. La primera ha sido siempre consustancial a su régimen jurídico. La segunda, se les atribuyó a partir de finales del siglo XVIII y se consolidó a lo largo del siglo XIX. Ambos aspectos producen consecuencias jurídicas y son determinantes en la configuración de su régimen regulatorio. RODRÍGUEZ BLANCO, M. (2015) Régimen jurídico de cementerios y sepulturas, Granada: Comares S. L., p. 49 inductivo-deductivo mediante la ilustración de los diferentes fenómenos jurídicos trascendentes a los derechos y las características definitorias de la propiedad cementerial, para propiciar su sistematización como institución jurídica, a partir de los conceptos, teorías y postulados en torno a la institución objeto de estudio y de su tratamiento conflictual. Y el análisis de derecho comparado que posibilitó contrastar y determinar las principales tendencias seguidas por ordenamientos pertenecientes al sistema de derecho latino o romano francés, dentro de ellos, España por las concepciones comunes en torno a la regulación jurídica de los cementerios públicos, heredadas desde la etapa colonial cubana. Se unen además las reglamentaciones francesa e italiana, al confluir de manera armonizada las proyecciones más actuales en torno a este derecho en el sistema normativo europeo. A su vez, y en el contexto latinoamericano, se trata la normatividad de México, Argentina y Chile, a partir de sus arraigadas concepciones en la regulación de los cementerios públicos, que ilustran las perspectivas normativas asentadas en América Latina, y muestran regulaciones de última generación en torno a la conformación jurídica del régimen aplicable a los cementerios públicos. El análisis se enfoca en cuanto a los sujetos que intervienen en la relación jurídica constituida en los cementerios públicos, los tipos de derechos reconocidos sobre bienes cementeriales, y por último en cuanto a la publicidad de su reconocimiento.

En correspondencia a los métodos descritos, se utilizaron las técnicas del análisis documental, que posibilitó acopiar la información necesaria sobre el tema, de análisis de reglamentos, ordenanzas y otras normas relacionadas con la regulación de los cementerios públicos en diferentes contextos geográficos y socioculturales, con el fin de desarrollar los objetivos propuestos, así como el procesamiento de información. Todo ello permitió identificar sus correspondencias y diferencias, para brindar veracidad a los resultados obtenidos. Además se emplearon medios auxiliares de apoyo para la recogida de los datos, entre ellos, documentos originales $\mathrm{y}$ fotografías. Se desarrollaron a su vez un conjunto de operaciones lógicas del pensamiento como son: generalización, interpretación y abstracción sin las cuales es imposible obtener los resultados esperados. 


\section{CONTENIDO DE LA REFLEXIÓN}

\section{Antecedentes histórico-culturales en la conformación doctrinal de los cementerios públicos}

Desde las primeras formaciones humanas, el culto a los muertos constituyó una constante que excedió al ámbito de la regulación legal. Cada una de las civilizaciones siguió determinados rituales y ofreció ciertos tratamientos a los restos humanos. Entre las primeras culturas de las que se tiene memoria, resalta, sin objeción alguna, Mesopotamia9. De acuerdo a los vestigios que de ella han perdurado, se conoce que los entierros se practicaban de conjunto a las pertenencias útiles o de valor, tanto sentimental como emocional del difunto. Sus prácticas funerarias eran muy populares; con ellas se honraban a los ancestros y entregaban ofrendas. En caso de tratarse del cabeza de familia, se le otorgaba al hijo mayor varón, la custodia de la unidad familiar.

En la sociedad egipcia ${ }^{10}$, tanto las tumbas como los templos constituían el núcleo de la vida urbana. En ellos se centró el origen e impulso de las grandes ciudades antiguas. Las primeras concepciones sobre los lugares de enterramientos se concibieron como motivos urbanos. Esta civilización siguió una elaborada serie de rituales que consideraban necesarios para asegurarse la inmortalidad. Estos ritos y protocolos incluían la momificación, la pronunciación de hechizos mágicos y la inclusión de objetos muy específicos en las tumbas, necesarios en la otra vida. Los entierros de los faraones eran muy elaborados, enaltecidos con grandes monumentos.

La primera pirámide tumba conocida es la pirámide escalonada de Saqqara, al noroeste de la ciudad de Memphis. El visir IMHOTEP ordenó que la pirámide fuera construida para el faraón ZoSER. El Imperio Antiguo egipcio culminó con la Gran Pirámide de Keops de Giza, la que data de alrededor de 2560 a.C. y es la pirámide más grande conocida. Durante el período del Imperio Nuevo, la principal forma de entierro de la élite fue en tumbas excavadas en la roca. Más de 60 tumbas se han hallado en la necrópolis conocida como el Valle de los Reyes. Entre ellas destaca la

9. Cifuentes, S. (1995) Derechos personalísimos, Buenos Aires: Astrea de A. y R. Depalma, p. 18 y ss.

10. Ídem, p. 21-22. del faraón TutanKamón, descubierta en 1922, que dio una visión detallada de las costumbres funerarias de los faraones egipcios.

En Roma ${ }^{11}$, los enterramientos inicialmente se efectuaron en el interior de las viviendas. Proscritos por leyes, estas costumbres resultaron fuentes de infección en las ciudades. La Ley de las Doce Tablas ${ }^{12}$ reguló aspectos sobre el tema, al prohibir los enterramientos e incineraciones de cadáveres en el recinto romano. Desde entonces, las inhumaciones se abrieron al campo, constituyendo jardines de pertenencia del difunto o en terrenos adquiridos con este propósito. La tumba, considerada como terreno donde se encuentra inhumado el cadáver de un hombre libre o esclavo, y en la que se construye un monumento funerario, se clasifica dentro de las cosas divini iuris, como "cosas religiosas" consagradas a los dioses inferiores, lo que la excluye del comercio entre los hombres ${ }^{13}$.

La jurisprudencia romana protegió el derecho de paso por terreno ajeno hasta la tumba (ius sepulcri), constituyendo una insipiente servidumbre de paso. También reguló la posibilidad de conversión de un "lugar puro" en donde no hay enterramientos, en "religioso", al sepultar en él un cadáver, y sustraerlo así del comercio. En tal sentido, definió al monumento funerario como lo que existe para conservar una memoria; distinguiendo sepulcros familiares y de los hereditarios. También se refirió a los cenotafios, o sepulcros vacíos, reconocidos como lugares puros y por ende susceptibles de enajenación ${ }^{14}$.

Por la tradición el emplazamiento de las tumbas en la Edad Media $^{15}$ había quedado

11. ARIÉs, P. El hombre ante la muerte, Madrid: Taurus Ediciones, p. 12. 12. En la Tabla $X$, referida al Derecho Sacro, se regula la prohibición de que sean quemados o enterrados en la ciudad los cadáveres, la prohibición de hacer hogueras o piras funerarias a cierta distancia de los edificios, las restricciones relativas a los gastos o lujos en los entierros, y la no usucapión de los terrenos sepulcrales. LEY DE LAS XII TABLAS, recuperado de: https:// www.academia.edu/37578109/LEY_DE_LAS_XII_ TABLAS.pdf (Consultado 23/5/2019).

13. DigeSTo, Libro XI, Título VIII, Fragmento 4, plantea: Longa possessione ius sepulcri non tribui ei, cui iure non competit, al decir que por la larga posesión no se concede derecho de sepulcro a quien por derecho no le compete. Cuerpo del Derecho Civil Romano, traducido al castellano del latín por KRIEGEL, HERMANN y OSENBRÜGGEN, Tomo III, 2 da parte, 1892, Barcelona: Jaime MoLINAS, Editor-Valencia, pp. 134-136.

14. Digesto, Libro XI, Título VII, Fragmento 2, Parágrafo 6; Fragmento 5 y Fragmento 6, Parágrafo 1. Ídem.

15. Esta etapa se extiende desde la época romana hasta el siglo XVIII, denominada como la del derecho del príncipe, durante 
delimitado por la intervención católica, como cosas religiosas para procurar la vida eterna. Se afianza entonces una fuerte sujeción al Derecho canónico, fundado con el Corpus Iuris Canonici, la Editio Romana y el Código de Derecho Canónico de 1917, cuyas normas concedían o negaban la sepultura eclesiástica. De acuerdo a estas doctrinas se excluían, entre otros: los infieles, judíos, apóstatas, herejes, cismáticos denunciados, o que profesaran herejía pública.

Igualmente condenaba a los suicidas, ladrones que mueran cometiendo delito, usureros manifiestos, a los muertos en torneos o desafíos y también sus padrinos. Este control, si bien procuró el sostenimiento y amparo del lugar de eterno reposo, fue ejercido por órganos eclesiásticos. Subordinados a la Iglesia, los cementerios estaban totalmente alejados del poder estatal. Se instaura entonces el Derecho eclesiástico en aquellos Estados que debían dictar normas para regular las manifestaciones del fenómeno religioso.

El siglo XVII trajo consigo una sociedad desvinculada sentimentalmente de sus restos ancestrales. Los monarcas y príncipes europeos, en disputa con la nobleza, lograron desligarse de las limitaciones que les venía imponiendo el derecho estamental (princeps legibus solutus); así amplían el poder del Estado, concentrando todas las prerrogativas estatales en su persona. En tanto, y al amparo de la Reforma católica, se inician las ampliaciones de iglesias de un modo generalizado en toda Europa. Estas condiciones propiciaron, que desde finales del siglo XVIII' ${ }^{16}$, se ordenara la función administrativa en la creación y administración de cementerios europeos extraurbanos. Con independencia a su condición pública o privada, quedaron sometidos a las autoridades municipales.

la cual no existían normas científico-jurídicas de carácter administrativo. IRARRÁZAVAL, A. (2018) Hacia un nuevo consenso en la regulación de los cementerios: la evolución de las normas civiles y canónicas a lo largo del S. XX, en Revista Chilena de Derecho, vol. 45, Núm. 1, pp. 33-56. DUBIEL, K. (2015) La privación de las exequias eclesiásticas en el Código de Derecho Canónico de 1983, en Revista Civilizar de Ciencias Sociales y Humanas. Núm. 15, pp. 37-46. JEMOLO, A.C. (1962) Lezioni di diritto ecclesiastico, Milano: Dott. A Giuffrè-Editore, p. 23. RoLLAND, L. (1938) Précis de droit administratif, 7ème édition, Paris: Dalloz , pp. 424 y ss.

16. Esta etapa abarca desde el siglo XVIII hasta el siguiente, se conoce como régimen de policía o del Estado gendarme, y se caracteriza por el predominio la idea de Estado. MoNACELLI, G. (1943) Elementos de Derecho Administrativo y legislación fiscal y aduanera, 3ra edición., Buenos Aires: Librería y Editorial "El Ateneo", p. 11

\section{El cementerio y los derechos sobre bienes cementeriales. Su concepción moderna derivada del Derecho administrativo}

Europa constituyó el escenario propicio para el surgimiento de los cementerios modernos, tal y como se conocen en la actualidad. La monarquía europea advierte las profundas afectaciones que a la salud genera la concentración de cadáveres en las ciudades. En Francia ${ }^{17}$, los cambios político-jurídicos de finales del siglo XVII permitieron el desarrollo del cementerio contemporáneo. La insalubridad de las ciudades provocó el debate del estado de los cementerios por la Corte del Parlamento francés en 1737. Así, mediante Edicto en 1763, se decide su traslado a las afueras de las ciudades.

En 1776, el Rey Luis XVI, prohibió las inhumaciones en las iglesias y ordenó la transferencia a plazos, de los cementerios fuera de las murallas. Esta posición condujo al traslado de unos 6 millones de restos humanos provenientes de los cementerios de toda la ciudad a las Catacumbas de París. Esos principios fueron sistematizados al término de la Revolución, mediante el Decreto del 23 Pradial año XII (12 de junio de 1804), fundamento de la legislación funeraria francesa.

Otro tanto sucede en España ${ }^{18}$, cuya situación de salubridad era semejante. En 1784, el rey Carlos III decide construir un cementerio para el Real Sitio de San Idelfonso, dotado de un Reglamento propio. Sin embargo, no fue hasta la promulgación de la Real Cédula del 3 de abril de 1787, que se materializó la prohibición de enterramientos intramuros. Esta Ordenanza Real acudía a la tradición y a las Partidas de Alfonso X, para combatir a quienes defendían los sepulcros intramuros. Si bien concretó el necesario traslado de inhumaciones, resultó imprecisa al no pautar las normas de su construcción.

La aplicación de esa Orden tropezó con la negligencia de las autoridades y la escasez de

17. BERTRAND, R. (2010) Estudio de los cementerios franceses contemporáneos. Los problemas de método, en Revista Trace, Núm. 58, diciembre, Centro de Estudios Mexicanos y Centroamericanos, México D.F., pp. 71-81. ARIÉS, Ph. El hombre ante...cit., p. 180.

18. GonzÁlEZ, A. (1970) El cementerio español de los siglos. XVIII y XIX. Madrid: Archivo Español de Arte. No.171, pp. 289-320. REY Don AlFonso X EL SABIo, Siete Partidas, cit., pp. 22-23. 
fondos. Así, en el siglo XIX, se sucedieron otras reales Órdenes recordando la prohibición y concediendo facilidades económicas. En 1833 se pone fin a estas discrepancias mediante Reglamento en el que se creaba una jurisdicción mixta eclesiástico-civil. El Municipio debía hacerse responsable de la construcción del nuevo recinto, y las autoridades eclesiásticas de su custodia.

Para la sociedad inglesa ${ }^{19}$, la solución a la insalubridad provocada por los enterramientos parroquiales, fue la autorización de cementerios privados. La situación requirió que en 1848 se sancionara Ley de Salud Pública, que inició el proceso legislativo de los cementerios británicos, a partir de su base higienista. Los actos funerarios se consolidaron en 1857, con el establecimiento de un sistema nacional integral de cementerios.

Los países germánicos ${ }^{20}$, por su parte, atravesaron esta situación de manera menos angustiosa. A raíz de la quiebra de los movimientos liberales de 1848 y las reformas sociales y políticas sucedidas, se forjó la necesidad de la regulación de los nuevos cementerios extraurbanos. Italia ${ }^{21}$, siguiendo esta línea, ponderó la Ley del 20 de marzo de 1865, denominada "Ley sobre la unificación administrativa del Reino". Con ella, se levantaron los cimientos del ordenamiento administrativo y se perfiló la regulación administrativa de los cementerios.

A partir del siglo $\mathrm{XIX}^{22}$, la mayoría de los antiguos cementerios parroquiales europeos se convirtieron en plazas, mercados o instalaciones eclesiásticas. Surgió así la segunda generación de nuevos cementerios modernos que se caracterizaron por su aislamiento de la población. Sus concepciones y tipologías fueron

19. KEITH-LUCAS, B. y RichaRdS, P.G. (1980) Historia del Régimen Local Inglés en el siglo XX. Colección "Administración y Ciudadano", trad. Joaquín HERNÁNDEZ, Madrid: Instituto de Estudios de Administración Local, p. 51.

20. El mayor exponente de estos escritores es LORENZ VAN STEIN al cual se debe un enorme Verwaltungslehre en 10 volúmenes que se comenzó a publicar en 1865. GIANNINI M.S. (1991) Derecho Administrativo, trad. Luis ORTEGA, vol. 1ro, Madrid: Ministerio de las Administraciones Públicas, pp. 61-62.

21. AlesSI, R. (1960) Sistema Istituzionale di Diritto Amministrativo, Milano: Dott. A Giuffrè-Editore, p. 20.

22. Esta etapa discurre desde el siglo XIX a nuestros días, se caracteriza por la idea del Derecho reduciendo la facultad discrecional del Estado. Sin embargo, a partir de 1914 podría tratarse de una nueva etapa caracterizada por la intervención administrativa en la vida de las naciones. MonaCELLI, G. Elementos de Derecho Administrativo...cit., p. 11. posteriormente expandidas al mundo entero, adoptando los diversos estilos modernos que sobre su constitución hoy existen.

\section{Entre la propiedad y la concesión: los derechos constituidos sobre sepulturas}

Para las sociedades civilizadas, el derecho del hombre a que su cadáver reciba sepultura, y no quede expuesto a la intemperie o al abandono, constituye un atributo o prerrogativa inherente a la personalidad ${ }^{23}$. Al ser el objeto de los cementerios la inhumación de cadáveres humanos, las sepulturas devienen en su concreción. Desde las primeras culturas, la determinación de lugares de enterramientos alentó la constitución de derechos subjetivos sobre los sepulcros que los componían.

Las sepulturas españolas ${ }^{24}$ se concedían en el régimen de propiedad a perpetuidad, lo que las hacía susceptible de enajenación. Así, estipulado en la ordenación de los cementerios municipales del siglo XIX, se establecía en diversos reglamentos de cementerios aprobados por los Ayuntamientos. Esta condición permitió su libre disposición, en consonancia a las regulaciones civiles. Los derechos otorgados a perpetuidad, en virtud del principio de confianza legítima, prevalecen con el respeto a las garantías reconocidas a favor del administrado. De esta forma, no cabe la aplicación retroactiva de las nuevas ordenanzas municipales que fijan un límite a la duración de las concesiones.

Francia ${ }^{25}$, por su parte, tuvo una similar concepción de los sepulcros. Entre el período de 1850 a 1870 y el de 1920 a 1950 , se sitúa la edad de oro de los cementerios franceses. Estas etapas estuvieron marcadas por la aparición de tumbas fuera de lo común por el tamaño, los materiales, las esculturas y características del desarrollo de la propiedad de la concesión entre las clases medias. En el transcurso de los

23. ORTEGA GARCÍA, E. (2016) El derecho a la sepultura y su contextualización normativa en el ordenamiento jurídico cubano. Tesis en opción al grado académico de Máster en Derecho Constitucional y Administrativo. Universidad de Oriente Cuba, pp. 35-42.

24. BALLESTERos, L.A. (2006) Los principios de irretroactividad y confianza legítima en el Derecho funerario: el régimen transitorio de los derechos de sepultura en la jurisprudencia, en Revista Española de Derecho Administrativo, Núm. 129, Madrid, рр. 173-197.

25. BERTRAND, R. (2005) Que de vertus.... Les épitaphes édifiantes des débuts du XIX e siècle, en BERTRAND R., ANNE C., y JEAN-NOËL $P$. Les narrations de la mort, Aix-en-Provence: Publications de l'Université de Provence, pp. 241-255. 
dos últimos siglos, los cementerios franceses se constituyen ampliamente por fosas comunes y tumbas simples en provecho de las concesiones temporales y a perpetuidad. Estas últimas constituyen el principal aspecto residual del estado antiguo del paisaje funerario.

Otro sentido diametralmente opuesto tomó la regulación de los derechos sobre las sepulturas alemanas $^{26}$, al enmarcarlos en el ámbito privado. Desde finales del siglo XIX, la privatización de tareas públicas transforma al Derecho administrativo alemán. Su concepción se basa en la idea de que los particulares, con su iniciativa y sus recursos, pueden cumplir los cometidos públicos de mejor manera que las autoridades administrativas. El empresario privado tiene una responsabilidad de cumplimiento, en tanto el Estado solo de garantía. Así, las sepulturas se conceden por particulares, dentro del régimen privado de administración de cementerios.

Las influencias europeas encontraron asidero en América con similar proyección. En Estados Unidos de América, durante la segunda mitad del siglo XIX, el Estado de Nueva York fue uno de los lugares mejor y más extensamente codificado. Como resultado, el Código Político de $1860^{27}$, constituye un manual de Derecho público administrativo, que especifica el desenvolvimiento del Estado. Es a partir de su artículo 1106 que ofrece una clara ordenación de los cementerios. De acuerdo a sus posturas, la adquisición de los cementerios debía realizarse a nombre del pueblo, siendo inenajenables, salvo resolución de autoridad comunal.

Más controversial ha sido el tratamiento de los sepulcros en Argentina. Importantes autores Como BARRAQUERo ${ }^{28}$, sostuvo que el sepulcro constituye un bien de naturaleza civil. Para ello, se fundamentan en el Decreto del 3 de septiembre de 1823, en el que se enuncian términos como

26. IBLER, M. (2016) Los nuevos retos y tendencias del Derecho administrativo en Alemania, en Revista IUSTA, Núm. 45, Bogotá, pp. 165-182.

27. El eminente jurista Dr. David DUDLEY FIELD, estuvo a cargo de su redacción e implementación. New York Field Codes Series. Volume V. State of New York. The Lawbook Exchange, Ltd.Clark, New Jersey-Biblio.com, recuperado de: https://www. biblio.com/bookstore/the-lawbook-exchange-ltdclark\&usg= AOvVaw0T64rKbVlf-ZY7I_NMSAXH (Consultado: 2/11/2018).

28. BarRaquero, Carette, ATtWell Ocantos, Requena (1912) Diccionario de Legislación Nacional y Provincial, Tomo II, Buenos Aires: Tipográfica Editora Argentina, pp. 295, 298 y 300. venta y compra de sepulturas. Ello significa que se trataba de bienes privados, criterio que también seguía la Ley Orgánica de la Municipalidad de Buenos Aires, No. 1260. En efecto, estos términos, en unión a otros como propiedad de las sepulturas, venta de nichos, panteones particulares, comprador de terreno para sepulcro, se empleaban con otras expresiones que contradecían a aquellas.

De la regulación administrativa de los camposantos modernos a partir del siglo XVIII, se evidencia que, a pesar de ser doctrina aceptada su sometimiento al servicio público, los derechos que sobre sus bienes se constituyeron no siempre guardaron esta misma esencia. Ello provocó su aprovechamiento individual desentendido de la unidad inmobiliaria. Precisamente, es la sepultura donde se concreta y materializada el servicio público de cementerio.

\section{La religión y sus nexos con la expresión actual de los cementerios públicos}

Desde el punto de vista de su origen, entre el cementerio y la religión existe una vinculación íntima. Precisamente, siendo el primero, la resultante de un fenómeno natural inexorable: la muerte, su aparición es inevitable en toda sociedad humana. En cambio, la religión es el resultado de una manifestación del espíritu, cuya expresión puede no haberse concretado en forma simultánea con la formación o aparición del grupo social, sino con el transcurso del tiempo. Tal como ocurrió también en otras religiones, los cristianos comenzaron a construir sus capillas en los cementerios. De este modo la iglesia, como formación social, surge como una dependencia del cementerio ${ }^{29}$.

En la religión judía ${ }^{30}$, la muerte representa una separación natural e inevitable entre lo material y lo espiritual. Tiene lugar cuando se ha cumplido con la misión que Dios encomendó en la tierra $\mathrm{y}$ marca el final del sufrimiento que se tiene en la vida. Entendiéndose de esta forma que la

29. Los sepulcros de San Pedro y San Pablo dieron lugar a las iglesias de su advocación. FERNÁNDEZ DE VELASCO CALVO, R (1935) Naturaleza jurídica de cementerios y sepulturas: historia y problemas jurídicos, Madrid: Revista de derecho privado, p. 91. 30. Sobre los rituales funerarios judaicos, véase el Libro de Números 19:14-19. Antiguo Testamento. Santa Biblia (1998) Versión Reina Valera Revisada en 1960, Estados Unidos de América: Sociedades Bíblicas Unidas, p.171. STEDMAN R. (2000) Principales postulados del movimiento judío, Nashville: Editorial Caribe Inc., p. 77. 
muerte no debería causar sufrimiento, aunque, en experiencia, sí lo causa. Hay un cierto grado de ambivalencia cuando se habla de lo que sucede al morir. Se considera por un grupo de creyentes la inexistencia de premios ni castigos. Otros sostienen que las recompensas pueden ser irse con Dios o reencarnar en una mejor persona.

Por su parte la religión católica ${ }^{31}$ considera a la muerte como una meta natural para todo ser humano. Es la separación del alma eterna del perecedero cuerpo físico. No se le debe temer porque marca el paso a un plano superior donde hay un descanso eterno. En lo relacionado con la expresión de la representación social, hay diversos ritos que se practican: se ofrecen misas, velorios y entierros, oraciones, velas y pésames. Todo ello para expresar solidaridad con la familia doliente, recordar al difunto y despedirse de él.

En el caso de los musulmanes ${ }^{32}$, la muerte es un regalo dado por Dios, al resultar el único modo de estar con Él una vez resucitados. Este ejemplo, junto a los anteriores, ilustra en alguna medida la relevancia religiosa de la muerte. Sin dudas, los aspectos tratados resultan apenas pinceladas de la amalgama de religiones y culturas que enfocan este acontecimiento desde diferentes ópticas, que hacen de la muerte y los enterramientos, un gran apoyo para aceptar la pérdida, y devienen en sucesos de trascendencia social.

\section{Los cementerios públicos como sujetos de derechos. ¿Su naturaleza jurídica es pública o privada?}

A partir de la secularización de los cementerios públicos, comienza una seria confrontación doctrinal en cuanto a su condición jurídica. Al efecto, se distinguen tres grupos que defienden posiciones doctrinarias opuestas. El primero ${ }^{33}$ les

31. Esta religión usa como estrategia el fallecimiento del hombre para conducir a un conocimiento-sentir, paz y gozo, asumiendo la muerte lúcidamente. VEIZAGA, K. (2005) Representación social de la muerte en distintas religiones, La Paz: Editorial Ajayu, p. 12.

32.Libro SURA II: 26. Corán, recuperado de http://www. nurelislam.com/coran/index.htm (Consultado: 4/3/2016)

33. Entre sus principales cultivadores destacan: BATBIE, A. (1888) Traité théorique et pratique de Droit Public et Administratif, Tome V, Paris: L. Larose et Forcel Libraires-Editeurs, p. 319; DUCROCQ, Th. (1900) Cours de Droit Administratif, Tome VI, No.2305, Paris: Ancienne Librairie Thorin et Fils. A. Fontemoings, Éditeurs, pp. 270-272; Journè, M. (1925) Précis de Droit Administratif, Paris Librairie de la Société du Recueil Sirey, p. 329; GUICCIARDI, E. (1934) Il Demanio, Milano: CEDAM, pp. 153-154. atribuye carácter de bienes privados del Estado; el segundo ${ }^{34}$ los considera bienes integrantes del dominio público; y, el último ${ }^{35}$, plantea una teoría ecléctica en la que los cementerios, sólo en parte, son bienes del dominio público, pues sus nichos y sepulcros, constituyen bienes privados del municipio y los concesionarios.

El fundamento privado de los cementerios se sustenta en que, al resultar éstos fuentes de recursos para las comunas, pueden otorgarse concesiones onerosas, que permitan al Estado recibir un beneficio económico. Tal análisis parte de la existencia de cementerios privados, sobre los que se ejerce la afectación al servicio de inhumaciones y el poder de policía. Por lo que estas potestades no resultan incompatibles con la propiedad privada.

Para GUICCIARDI ${ }^{36}$, el carácter privado de los cementerios se debe a que la actividad del Estado respecto de los cementerios no es exclusiva de él, pues también existen cementerios particulares. Pero como la exclusividad de las respectivas funciones del Estado, es uno de los requisitos que deben concurrir para que la cosa pueda considerarse demanial, debe negarse esta condición a los cementerios. Por su parte, BARRAQUERO $^{37}$ le atribuyó este carácter, basado en las leyes dictadas al respecto, que disponían la venta de las parcelas para construir sepulcros, al considerarlas una desafectación del respectivo bien público.

En los aspectos referidos, debe valorarse que los bienes demaniales no requieren necesariamente la improductividad, o que las concesiones de uso sean

34. Sus exponentes son: ProudHon, M. Traité du Domaine Public... cit., Tome I, pp. 460-462; MAYER, O. El derecho administrativo... cit., pp. 121-122 y 236; HAURIOU M. Précis de droit...cit., p. 826; LAUBADÈRE A. (1936) Les concessions dans les cimetières, en Revue du droit public et de la science politique, Paris: Dalloz, pp. 612- 620; JANSSE, L. (1938) Les traits principaux du régime des biens du domaine public, Paris: Dalloz, pp. 125-126; FERNÁNDEZ DE VELASCO CALVO, R. Naturaleza jurídica de cementerios...cit., pp. 203-205; CAEtano, M. (1970) Manual de Direito Administrativo, Tomo I, Rio de Janeiro: Companhia Editora Forense, p. 206; LAFAILLE (1944) Tratado de los Derechos Reales, Tomo II, No. 1016, Buenos Aires: Tipográfica Editora Argentina, p. 161.

35. SALVAT R. (1923) Tratado de Derecho Civil Argentino (Derechos Reales), Tomo 1, No. 1436, Buenos Aires: Tipográfica Editora Argentina, p.751. PÉREZ GÁLVEZ, J. F. (1997) El sistema funerario en el Derecho español, Pamplona: Aranzadi, pp. 335 y ss.

36. GUICCIARDI, E. Il Demanio, cit., pp. 74-75.

37. BARRAQUERo, J. (1889) Cuestiones Jurídicas, 2 da edición, Buenos Aires: Tip. Lit. y Enc. del Colegio PIO IX de Artes y Oficios, p. 144. 
gratuitas. Además, en el caso de los cementerios privados, no puede hablarse de dominio público, al no concurrir uno de sus elementos indispensables: el elemento subjetivo. A ello se suma que la condición del cementerio ha de encontrarse en sí mismo. No es público o privado porque pertenezca o uno u otro sujeto, pues la realidad jurídica positiva no distingue, refiriendo simplemente, cementerio. Por eso, el poder de policía se manifiesta sobre toda clase de actividades, ya sean públicas o privadas ${ }^{38}$.

Por su parte, la teoría ecléctica que distingue el régimen público del cementerio y el dominio privado sobre sepulcros, dio lugar a diversas corrientes doctrinales que intentaron justificar su naturaleza jurídica. Algunos autores ${ }^{39}$ pretendieron resolver esta cuestión sosteniendo una diferenciación entre el derecho de acceso al servicio (cementerio), y el uso privativo sobre el bien de dominio público (sepultura). Tal distinción apunta a que la naturaleza de las sepulturas privadas en los cementerios municipales no consiste en derechos reales administrativos, sino en una propiedad sui generis, criterio que siguieron algunos tribunales ${ }^{40}$.

Otros expositores ${ }^{41}$ consideraron al derecho de sepulcro como un contrato innominado celebrado entre el Estado y el particular. Por último, se suma la opinión que igualó al sepulcro con un bien de derecho civil ${ }^{42}$, estableciendo una propiedad común sobre el sepulcro. Se impone entonces la doctrina del dominio público. El cementerio constituye por sí y en cuanto a quienes lo utilizan, una situación objetiva, reglamentaria e impersonal. Se trata de un servicio sometido al régimen de derecho público, invulnerable al derecho privado, bajo el

38. Villegas Basavilbaso, B. Derecho Administrativo, Tomo IV, cit., p. 403.

39. SALVAT R. Tratado de Derecho Civil...cit., p.751. PÉREZ GÁLVEZ, J. F. (1997) El sistema funerario en el...cit., p. 338.

40. Al respecto, cabe mencionar la postura del Tribunal Supremo español, el que en la Sentencia de 11 de julio de 1989 (RJ 5746) razona "(...) sobre las sepulturas no cabe la propiedad privada en sentido estricto y en idéntico sentido que sobre cualquier bien inmueble, pues obvia y forzosamente ésta había de ser una propiedad especial y sui generis, en la regulación de la cual convivían derechos privados con disposiciones de derecho público (...)". Comentada en MARIENHOFF, M. S. Tratado de Derecho Administrativo...cit., Tomo V, pp.259-260.

41. TRotabas, L. (1924) De l'utilisation du domaine public par les particuliers; essai de classification juridique, Paris: Librairie Dalloz, pp. 142-156; LE BALLE, R. (1924) De la nature du droit du concessionnaire de sépulture, Paris: Librairie Dalloz, pp. 108-109.

42. BIELSA, R. (1956) Derecho administrativo, Tomo III, 5ta Edición, Buenos Aires: Depalma, p. 444. amparo y protección de órganos administrativos en materia de interés colectivo, relacionado con los particulares mediante actos administrativos provocados por ellos ${ }^{43}$.

\section{Límites y contenido de los derechos reconocidos en los cementerios públicos. Otros derechos en colisión}

La esencia demanial de los cementerios públicos, atribuye igual naturaleza jurídica a las sepulturas incorporadas a ellos. Tal situación pondera un servicio público destinado a su uso privativo de un bien público, que deviene en el acto jurídico en cuyo mérito los particulares pueden adquirir derechos. Por esta razón, no podrá configurarse como compraventa u otro contrato traslativo de dominio, mucho menos de arrendamiento. Tratándose de cementerios públicos o privados, la actividad reviste calidad de servicio público, por lo que están sujetos al poder de policía mortuoria de la Administración. Así, se garantiza que la sepultura sea únicamente utilizada de acuerdo a su fin, por personas facultadas y a través de los medios establecidos en la normativa vigente en el lugar ${ }^{44}$.

En este sentido, MARIENHOFF ${ }^{45}$ identifica al osario o fosa común, como lugar colectivo de inhumaciones, otorgado mediante un uso común del dominio público, cuyo emplazamiento colectivo no genera intereses particulares. En tanto, al resultar los nichos inhumaciones que se individualizan, provoca que sobre ellos se establezca un uso especial, otorgado mediante concesión. Por otra parte, FERNÁNDEZ DE VELASCO $^{46}$ es más claro cuando reconoce los usos privativos temporales y a perpetuidad, como medios de expresión de derechos sobre sepulturas. Al efecto distingue tres clases, unas en todo caso perpetuas (concesiones), otras perpetuas o temporales (concesiones), y las últimas temporales solamente (permisos de uso), criterio al que se afilia la presente investigación.

Desde estos criterios, el uso privativo se otorga mediante el permiso de uso aplicado

43. FERNÁNDEZ DE VELASCo CALVo, R. Naturaleza jurídica de cementerios...cit, p. 250.

44. Ídem, p. 162.

45. Marienhoff, M. S. Tratado de Derecho Administrativo...cit., Tomo V, pp. 259-260.

46. Fernández de Velasco Calvo, R. Naturaleza jurídica de cementerios...cit, pp. 210-211. 
por la Administración para que los usuarios aprovechen y usen los cementerios, mientras la concesión de uso para actividades de importancia jurídica-económica-social. El permiso, como indica GaRRIDo FALLA ${ }^{47}$, está sometido a la posibilidad de que la Administración en cualquier momento pueda revocarlo por razones de interés público, sin derecho alguno del particular a indemnización; es decir, se otorgan a título de precario. En cambio, desde una perspectiva amplia, la concesión ${ }^{48}$ genera el nacimiento de un derecho para determinada persona, ya porque se lo otorga la Administración Pública, ya porque estaba establecido en las normas positivas, pero requiere de un acto administrativo para hacerse efectivo.

Cabe entonces delimitar los tipos de sepulturas en los que serán utilizados uno u otro medio de uso. Por un lado, el uso de fosas u osarios comunes y nichos, será autorizado a través de un permiso. En cambio, el uso de la tierra como sepultura y sepulcros, entendidos como bóvedas, panteones o mausoleos, serán autorizados mediante un acto concesional. En este entorno, la concesión, al contrario del permiso, constituye un poder jurídico sobre la cosa, de la que una parte será dejada al concesionario para realizar un uso especial. Mientras ese derecho esté en vigencia, es oponible a todos, incluso al Estado concedente, por lo que se otorga un verdadero derecho subjetivo para su concesionario, conformándose como un derecho real administrativo ${ }^{49}$.

El derecho de los permisionarios, se enmarca en un uso exclusivo y excluyente. Ello conlleva a que desde su otorgamiento, para la custodia, guarda y depósito de cadáveres, se excluye cualquier otro fin para el cual pudiera destinarse. Bajo la nota de precariedad, la Administración se reserva el derecho de establecer un término de duración, y extinguirlo unilateralmente. Esta situación justifica que, para la utilización de fosas comunes y nichos, es la Administración quien asume su edificación y emplazamiento. Por tanto, a pesar de que su uso pueda disponerse de

47. GARRIDo FALLA, F. (1986) Tratado de Derecho Administrativo, Volumen II (Parte General: Conclusión), 7ma edición, Madrid: Centro de Estudios Constitucionales, p. 471.

48. Matilla, A. Fundamentos del régimen jurídico de las concesiones...cit., p. 36.

49. MAYER, O. El derecho administrativo...cit., Tomo III, p. 248; GONZÁLEZ, J. (1975) Los derechos reales administrativos, Madrid: Civitas S.A., p. 106. forma gratuita u onerosa (tarifas), no genera la posibilidad de trasmisión a terceros. Llegado su término, salvo renovación, los restos se depositan en el osario municipal, o en la urna de sus deudos.

Por otro lado, el derecho de los concesionarios ${ }^{50}$ implica, además del descrito uso exclusivo y excluyente, la atribución de levantar la construcción o monumento funerario. Esta facultad deviene en un derecho inherente al uso mismo de la concesión. En estos casos, debe conllevar la posibilidad de construir los elementos indispensables para la consecución del fin para el cual se otorgó. Además, genera la posibilidad de su trasmisión a terceros por acto inter vivos o mortis causa, siempre que la concesión no lo prohíba, se respeten sus condiciones, y lo consientan los reglamentos municipales. Pueden constituirse a título gratuito u oneroso, cuando se pacta algún precio, este será un simple canon, que no debe confundirse con impuesto o tasa.

Debe advertirse la existencia de una corriente doctrinaria $^{51}$ que excluye a las sepulturas del régimen concesional. En ella se enfatiza que la concepción de la sepultura no se resuelve con el régimen del dominio público, sino con el del servicio público. Por lo que, al considerarla como un servicio, su naturaleza de cosa sagrada, no le permite ser objeto de contrato, ni de legado, ni susceptible de prescripción, embargo o hipoteca. Por tanto, su otorgamiento constituye una prestación singular de un servicio público que se identifica con la utilización excluyente del bien. Al alejarse de la concepción de uso privativo de las sepulturas, a este criterio no se acoge la presente obra.

Otra cuestión que resalta en la doctrina es el otorgamiento de concesiones de forma temporal o perpetua. Al respecto, existen dos corrientes que, si bien coinciden en la temporalidad de las concesiones, se bifurcan en cuanto a su perpetuidad. El primer grupo ${ }^{52}$ plantea que la perpetuidad del

50. Marienhoff, M. S. Tratado de Derecho Administrativo...cit., Tomo V, pp. 187-189.

51. ZanobINI, G. Curso de Derecho...cit., p. 106; ALESSI, R. (1970) Instituciones de Derecho Administrativo, Tomo II Barcelona: Bosch, p. 411; LÓPEZ J.A. y SÁNCHEZ, J.L. La concesión administrativa en la esfera local...cit., pp. 320-321.

52. Así lo sostienen además VILLAR PaLASÍ, J.L. Concesiones administrativas...cit., p. 756; GARCÍA DE ENTERRÍA (1997) El dogma de la reversión de concesiones, en GARCÍA DE ENTERRÍA E. y FERNÁNDEZ, T.R. (1997) Curso de Derecho Administrativo, Tomo I, Octava Edición, Madrid: Civitas, p. 564; ALBI, F. (1960) Tratado de los modos de gestión de las Corporaciones locales, 
derecho de uso equivale a una enajenación de la cosa respectiva, chocando con el carácter de los bienes públicos. La existencia de un plazo cierto prorrogable, al decir de PARADA ${ }^{53}$, constituye un requisito estructural de la concesión, que asegura la continuidad de la prestación del servicio, y garantiza los derechos del concesionario. De esta forma, la temporalidad permite establecer un vínculo con el concesionario que le impide abandonar la concesión.

Los seguidores de esta corriente se basan en la significación del plazo para el cumplimiento y extinción de la concesión. Este puede concretarse con el señalamiento de un límite temporal de ejercicio de los derechos y facultades que la concesión otorga al concesionario. El plazo cierto se comporta como una doble garantía para el concesionario, pues no podrá ser obligado a desempeñar la concesión por más tiempo del pactado. A la vez, le permite calcular la indemnización que le corresponde si la Administración procede a un rescate anticipado. $\mathrm{Su}$ término es no sólo cierto, sino fijo o determinado (dies certus an et quando). Así mismo, en el aspecto jurídico constituye una garantía del respeto de la Administración hacia el ejercicio de esos derechos y facultades.

Visto así, la temporalidad deviene en principio estructural en la relación concesional. Sin embargo, encuentra una excepción en algunas de las concesiones demaniales, ante la posibilidad de constituirse sin un plazo o término fijado. En tales casos, se configuran las concepciones perpetuas de sepulturas, acogidas por el segundo grupo de tratadistas $^{54}$, que reconocen la validez jurídica de la perpetuidad en las concesiones de uso. Para ello se basan en que en tales casos, las concesiones mantienen identidad substancial, igual naturaleza, cuya única diferencia consistirá en su duración.

\footnotetext{
Madrid: Aguilar, p. 650; LÓPEZ J.A. y SÁNCHEZ, J.L. La concesión administrativa en la esfera local...ob.cit., p.189-191.

53. PARADA, R. (2004) Derecho Administrativo, Tomo I, Parte General, 15a edición, Madrid: Marcial Pons, p. 347.

54. Entre sus principales exponentes destacan: ARBUS (1924) Concessions dan cimentières...cit; PACELLI, F. (1918) Le acque pubbliche, Terza edizione, Torino: Cedam, pp. 252-253 y 293; VITALE, A. (1920) Il regime delle acque nel diritto pubblico e privato italiano, Milano: Hoepli, p. 362; BIBILONI, J.A. (1929) Anteproyecto de reformas al Código Civil Argentino, Tomo III, Buenos Aires: Valerio Abeledo, p. 29; LAZO PREUSS, S. (1930) Régimen legal de las aguas corrientes, Santiago de Chile: La Ilustración, pp. 159-160; FERNÁNDEZ DE VELASCO CALVO, R. Teoría jurídica de las concesiones...cit.; LAUBADÈRE A. Les concessions dans les cimetières...cit., p. 622
}

La concesión de uso otorgada a perpetuidad, es compatible con el régimen del dominio público. Esta aseveración se sustenta en que tal condición provee la seguridad jurídica que garantiza el bienestar y tranquilidad individuales. Al resultar constitutivas de un derecho de uso acorde a su destino, no son traslativas de dominio. Su situación jurídica se equipara al tratamiento de las concesiones temporarias susceptibles a renovaciones sucesivas. Además, a pesar de su condición, el Estado puede imponer sobre ellas las modificaciones que se deriven de nuevas necesidades sociales. Por último, la perpetuidad no impide la revocación de la concesión, cuando razones de interés público así lo requieran.

Desde estas opiniones debe entenderse que, en el régimen concesional de las sepulturas, la renovación tutela la voluntad de los familiares, de hacer reposar los restos de sus seres queridos en un determinado lugar. Con ella se garantiza a su vez, la transmisibilidad del derecho y el uso privativo de sus construcciones como panteones y mausoleos. Para el cementerio, como bien de dominio público, la renovación de una concesión una vez expirado el plazo de duración, contribuye al cumplimiento de su finalidad concreta. Esta debe tener lugar, siempre que no existan razones objetivas de interés público que lo impidan, en cuyo caso concreto, la Administración tendría que acreditarlas ${ }^{55}$.

De todo lo anterior se infiere que la posesión desarrollada tanto por permisionarios, como concesionarios, no puede ser civil, al carecerse de la intensión de apropiarse de la cosa. Tampoco puede poseerse en otro concepto que en el de tenedor que la conserva o disfruta, por encontrarse el dominio en otra persona. No obstante, se les reconoce el derecho a promover acciones posesorias contra terceros, respecto al uso de la cosa. Ello se debe a que poseen la quasi possessio iuris del bien, con relación a terceros, tratándose de un estado de señorío dotado de consecuencias posesorias. Su procedencia requiere que recaiga sobre derechos que se ejerzan en forma continua, prolongada y efectiva, que sean reales y que estén en el comercio, en este caso, en el comercio del Derecho Administrativo ${ }^{56}$

55. RodRÍGUEZ BLANCO, M. Régimen Jurídico de...cit., pp. 72 y 109. 56. FERnÁNDEZ de VeLASCo CALVo, R. Naturaleza jurídica de cementerios...cit, pp. 211-212 y 239-241. 
En el contenido de ambos medios de uso privativo se enmarcan las servidumbres administrativas que en su utilización se dispongan, siempre que sean compatibles con el fin que motiva la afectación de la cosa. De igual forma, se ejercen las potestades que protegen el pleno dominio de la Administración concedente y los derechos de los particulares usuarios del servicio de cementerio. Todo ello con independencia de las potestades de las entidades gestoras del servicio, cuyos límites y contenido dependerá de sus estatutos y los acuerdos municipales, en armónica relación de intereses públicos y privados.

\section{La relación jurídica en sede cementerial. Sus elementos constitutivos}

El uso privativo de los bienes que integran a los cementerios públicos, entraña una relación jurídica especial entre particular y Administración. Permisionaria o concesional, esta relación implica una bilateralidad entre ambos sujetos, desde el punto de vista sustancial y formal. Surgida del acto administrativo por el que se otorga, genera derechos y obligaciones vinculantes, cuyo contenido concreto vendrá determinado además por la reglamentación general del recinto cementerial. Ello se debe a que en su formalización deben concurrir las voluntades de las partes intervinientes en la relación, aunque, evidentemente por el ámbito objetivo y las consecuencias de la relación, se trata de una participación desigual ${ }^{57}$.

Entonces, a la Administración Pública le corresponderá un mayor poder de decisión. Sus consecuencias trascienden a las partes, al afectar el uso y trasmisión de estos bienes a terceros. Es criterio de esta investigación la coincidencia en el régimen jurídico de los cementerios públicos, del tratamiento de concesiones y permisos de uso de sepulturas. Aunque independientes en su contenido y alcance, encuentran en este régimen un similar tratamiento constitutivo. Es por ello que, en la estructuración de la relación jurídica que en esta sede se suscita, resulta apropiable el diseño de la naturaleza jurídica de las concesiones administrativas observado por el profesor MATILLA CORREA ${ }^{58}$.

57. RodRÍGUEZ BLANCO, M. Régimen Jurídico de...cit., p. 112. 58. Matilla, A. Fundamentos del régimen jurídico de las concesiones...cit., p. 52.
De esta forma, puede identificarse como sujeto activo de la relación al Estado, quien ejerce su función directa, a través de las empresas y entidades que a tales efectos crea, resultando un sujeto determinado. Al no existir la res nullius, se impide que cualquier persona pueda apropiarse de ellos, en cuyo caso no habría razón para el dominio público. Existen dos corrientes doctrinales en cuanto a la titularidad del dominio público, que se atribuye por un sector al pueblo, y por otro al Estado ${ }^{59}$.

Coincide esta investigación con las consideraciones del profesor VILLEGAS BASAVILBASO $^{60}$ al expresar que los exponentes del pueblo como sujeto demanial, consideran bienes públicos únicamente a los afectados al uso directo de la colectividad, no a los bienes patrimoniales del Estado afectados al uso indirecto (servicio público), sobre los cuales el Estado tiene un verdadero derecho subjetivo. El sujeto pasivo o usuario en esta relación, a diferencia de los usos comunes, no será indeterminado o genérico, constituido por la colectividad. En todo caso es específico, representado y compuesto por los titulares de los derechos otorgados por el Estado. Cuestión que permite individualizar al usuario ${ }^{61}$.

En este desigual ámbito, la Administración Pública mantiene las facultades precisas para asegurar el cumplimiento del fin contemplado por el ordenamiento. Así, ejerce la función administrativa, a partir del conjunto de potestades ya referidas, las que, inherentes a su actuar, coadyuvan a la defensa del patrimonio demanial. Por su parte, el usuario, tiene un carácter intuitu personae que, si bien permite la transmisibilidad de los derechos derivados de la relación jurídica, los limita al requerir autorización administrativa. A pesar de la poca trascendencia que para esta relación jurídica posee, esta condición origina derechos para el concesionario. En este contexto, estos derechos

59. En esta doctrina coinciden: RANELLETTI, O. (1897) Concetto, natura e limiti del demanio pubblico, en Rivista Giurisprudenza Italiana, Torino: Unione Tipografico-Editrice Torinese, p. 374. GUICCIARDI, E. Il Demanio...cit., p. 28; BALLBÉ, M. (1948) Concepto del Dominio Público, Barcelona: Bosch, p. 9; LAUBADĖRE, A. (1958) Droit Administratif Spécial, Paris: Presses Universitaires de France, p. 738; GARCÍA DE ENTERRÍA E. y FERNÁNDEZ, T.R. Curso de Derecho... cit., p. 48; GARRIDO FALLA, F. Tratado de Derecho...cit., p. 478.

60. Villegas Basavilbaso, B. Derecho Administrativo, Tomo IV, cit., p. 170.

61. MARIENHoff, M. S. Tratado de Derecho Administrativo, Tomo V, cit., p. 153. 
emergentes devienen en un poder jurídico sobre la parte de la cosa pública que le ha sido entregada ${ }^{62}$.

\section{Los bienes demaniales en la relación jurídica cementerial. Implicaciones y trascendencia}

La relación jurídica cementerial tiene por objeto el conjunto de bienes demaniales integrados a los cementerios susceptibles de un uso privativo. Estos bienes se componen de cosas corporales, que a su vez se subdividen en bienes muebles e inmuebles. En cuanto a su reconocimiento, existe disparidad de posiciones doctrinales. Algunos autores $^{63}$ afirman que solamente los bienes inmuebles pueden constituirse como parte del dominio público. Otros ${ }^{64}$ tratadistas defienden que lo accesorio integra el dominio público, siempre que contribuya de forma permanente, directa e inmediata, a que el bien demanial cumpla su destino y satisfaga los fines que motivan su institución. Por lo que, si lo accesorio fuere esencial para que el bien público cumpla su destino, también revestirá calidad demanial.

Este último grupo fundamenta que la categoría demanial se adquiere de forma física, cuando la cosa accesoria está adherida a la principal, o moral, cuando solo depende de ésta. Al respecto, y en lo concerniente a este tema, no debe confundirse la accesión civil, donde el propietario de un fundo lo es también de la superficie y el subsuelo, con la théorie de l'accesoire del Derecho francés, según la cual, para que una construcción sobre el dominio público pueda considerarse como parte de éste, debe haber una relación funcional e indisociable entre ambos bienes ${ }^{65}$.

62. LóPEZ J.A. y SÁNCHEZ, J.L. La concesión administrativa en la esfera local...cit., p. 147. MAYER, O. El derecho administrativo... cit., Tomo III, p. 248.

63. DuCRoco, Th. Cours de Droit...cit., Tome IV; BERTHÉLEMY H. (1910) Traité elementaire de Droit Administratif, Paris: Rousseau \& $C^{i e}$ Éditeurs, p. 478, 481-482; JouRnè, M. Précis de Droit...cit., p. 261; PrEsuTTI, E. (1931) Istituzioni di Diritto Amministrativo Italiano, Volume primo, Milano: Casa Editrice Giuseppe Principatto - Messina, pp. 220-223; GUICCIARDI, E. Il Demanio...cit., pp. 5, 16, 24-26, 28 y 70; CAETANo, M. Manual de Direito...cit., p. 178.

64 Entre los autores que defienden esta corriente doctrinal destacan: SÁNCHEZ MoRóN, M. (1997) Los bienes públicos, Madrid: Editorial Tecnos S.A., p. 37; MARIENHOFF, M. S. Tratado de Derecho Administrativo, Tomo V, cit., pp. 36-38; EscolA, H.J. (1989) El interés público como fundamento de Derecho Administrativo, Buenos Aires: Ediciones Depalma, p. 201; VILLEGAS BASAVILBASO, B. Derecho Administrativo...cit., Tomo IV, p. 267

65. ChARLES, H. (1974) Accessoire et domaine public en droit administratif français, en Mélanges Michel Stassinopoulos, Paris:
Se hace necesario entonces, recurrir a un criterio rigurosamente objetivo: todos los bienes muebles que contribuyan al cumplimiento del fin público, y se transforman en inmuebles por accesión física o moral de un inmueble público, forman parte del dominio público. La práctica jurídica indica que para formar parte del dominio público, los bienes inmuebles por accesión deben tener carácter permanente e irremplazable, no pudiendo tratarse de cosas consumibles, ni fungibles. Esas condiciones se cumplen en los bienes muebles incorporados a los cementerios, pues, aun cuando no afectan al uso de la comunidad sino al individualizado, conforman el dominio público ${ }^{66}$.

Los argumentos estudiados, abren el diapasón para definir los bienes que integran el objeto de la relación jurídica analizada. Esta situación posibilita la inclusión en esta modalidad de tantos bienes como sean posibles instalar o adecuar al entorno del cementerio. Todo ello, siempre que contribuyan permanente, directa e inmediatamente al cumplimiento de sus fines. Aventurarse a la determinación de los bienes inmuebles por accesión, en el entorno cementerial, ya es de por sí un tanto arriesgado. Sin embargo, la diversidad de estos bienes justifica la necesidad de someterlos al régimen jurídico especial de los cementerios.

\section{Causalidad en la relación jurídica en sede cementerial}

El elemento causal de la relación jurídica en sede cementerial, resulta un derecho nacido a la vida jurídica, bajo los principios y reglas publicísticas. Esto conlleva a que las relaciones del usuario con otros particulares se rigen por el Derecho privado, siempre que no exceda los límites trazados por el Derecho Administrativo. De esta forma, es la Administración quien, a partir de la reglamentación interior de los cementerios, aprobados por la corporación municipal de la que depende la necrópolis, establece la identificación de los servicios, las condiciones de uso y la extensión de los derechos reconocidos a los usuarios (personas naturales o jurídicas).

\section{LGDJ, pp. 187-192.}

66. DiEz, M.M. (1940) Dominio Público. (Teoría General y Régimen Jurídico), Buenos Aires: Abeledo- Editor, p. 225 VILLEGAS BASAVILBASO, B. Derecho Administrativo...cit., Tomo IV p. 100; MARIENHOFF, M. S. Tratado de Derecho Administrativo... cit., Tomo V, p. 37 
En este contexto, el Derecho privado en el uso del bien cementerial, queda limitado a la conservación de cadáveres y restos humanos, de acuerdo con las condiciones y duración de su otorgamiento. También y tratándose de concesiones, dispone la ordenación de inhumaciones, exhumaciones, reducción de cadáveres y otras prestaciones reconocidas. Determina a su vez los epitafios, recordatorios, emblemas y símbolos de la unidad de enterramiento, previa autorización de la Administración, y de acuerdo con las normas que rijan la materia ${ }^{67}$.

Para estas y otras cuestiones que involucra la solución de conflictos originados en torno a los bienes cementeriales, ha sido la Administración Pública, en su función de sujeto activo representante del poder estatal, quien ha desempeñado una encomiable labor. De esta forma, se erige como máxima juzgadora de estos asuntos, en observancia a las disposiciones vigentes al respecto ${ }^{68}$. En este sentido, debe señalarse el entramado constitucional, penal, civil y administrativo que debe contener las disposiciones en torno a la regulación del uso de los bienes cementeriales.

En otro ámbito, ha de apreciarse que la relación jurídica cementerial puede extinguirse por diversas causales. Considerando que ella puede verse constituida tanto por permisos, como por concesiones, la figura básica en la extinción de las primeras es el vencimiento de su plazo. En las segundas, opera la caducidad ante el incumplimiento grave de las obligaciones del usuario, siempre que dicho incumplimiento le sea imputable. También la relación concluye con la muerte o extinción de la personalidad jurídica, sin autorización previa ${ }^{69}$. Este supuesto, un sector de la doctrina ${ }^{70}$ lo cataloga como rescisión de pleno

67. RodRÍGUEZ BLANCO, M. Régimen Jurídico de...cit., pp. 99-101 y $112-115$.

68. Martín-Retortillo, S. (1963) Responsabilidad de la Administración pública por lesión de intereses legítimos, en Revista de Administración Pública, Núm. 42, Madrid, pp. 453 y ss; 69. MARIENHOFF, M. S. Tratado de Derecho Administrativo, Tomo V, cit., pp. 192-193; RODRÍGUEZ BLANCO, M. Régimen Jurídico de... cit., p. 117; BERTHÉLEMY, H. Traité elementaire de Droit...cit., $p$. 718; ZaNoBinI, G. Curso de Derecho Administrativo, Tomo IV, cit., p. 74; PACELLI, F. Le acque pubbliche...cit. pp.128-133.

70. VILLEGAS BASAVILBASO, B. Derecho Administrativo...cit., Tomo IV, pp. 263-265; SAYAGuÉS LASo, E. (2010) Tratado de Derecho Administrativo, Tomo II, 9na edición, Montevideo: Fundación de derecho, y aplican a este propio medio de extinción, el concurso de la voluntad de ambas partes para dejar sin efecto la concesión: el mutuo acuerdo.

Asimismo, puede extinguirse por revocación del derecho por razones de interés público o ilegitimidad, en supuestos de concesiones otorgadas con vicios legales, sobre los requisitos esenciales para la existencia válida del acto. La renuncia, como causa extintiva de la concesión cementerial, se aplica en razón de su otorgamiento en interés privado del concesionario. También opera el rescate de la concesión, previa indemnización, o revocación unilateral de la autorización ${ }^{71}$.

En este aspecto es importante señalar las reflexiones del profesor Matilla CoRREA ${ }^{72}$, al evaluar la tendencia doctrinal que considera al rescate como una expropiación forzosa por causa de utilidad pública. Al respecto, la investigación se afilia a su criterio, al apreciar que ambas figuras -al decir del académico- comparten sus líneas estructurales fundamentales; por lo que se acepta que el rescate se inserte dentro de esa figura más general que es la expropiación forzosa y que se individualizará a raíz del tipo de derecho patrimonial que afecta y el tipo de relación en el que actúa. Por último, deviene en causal de extinción, cualquier otra causa prevista en las condiciones generales o particulares por las que se rija la concesión o el permiso.

\section{La regulación administrativa de los cementerios públicos desde una perspectiva comparada}

En el ámbito internacional, la protección más significativa de cementerios y sepulturas es la que se ofrece en el marco de los cuatro Convenios de Ginebra, de 12 de agosto de 1949. Su contenido versa sobre la protección internacional del derecho de la persona a recibir

la Cultura Universitara ( $F C U), p .78$

71. MARIENHoff, M. S. Tratado de Derecho Administrativo, Tomo $V$, cit., p. 192; RESTA, $R$. (1942) La revoca degli atti amministrativi, Parte Generale, Milano: Dott. A. Giuffrè - Editore, pp. 63-69, BALDI PAPINI, U. (1956) L'annullamento d'ufficio degli atti amministrativi invalidi, Rist. varitipica dell'ed. del 1939, Milano: Firenze Cya, pp. 56-64; RANELLETTI, O. (1945) Teoria degli atti amministrativi speciali, Settima edizione riveduta e integrata Milano: Dott. A. Giuffrè - Editore, pp. 129-133.

72. Entre sus seguidores JEZì, FLEINER, CAVALCANTI, GARCÍATREVIJANO y sus oponentes MAYER, BERTHÉLEMY, LAUBADËRE, GRECA. Matilla, A. Fundamentos del régimen jurídico de las...cit., p. 96. 
sepultura digna. Tutela que exige la protección de los lugares de enterramiento ${ }^{73}$. Desde este paradigma, se instrumentan regulaciones nacionales, con el fin de brindar respaldo legal a su constitución y funcionamiento.

En el presente estudio se utiliza como referente a la legislación española, por las concepciones comunes heredadas desde la etapa colonial cubana. Se unen además las reglamentaciones, francesa e italiana, al confluir de manera armonizada las más actuales proyecciones en el sistema normativo europeo. A su vez, y en el contexto latinoamericano, se trata la regulación de México, Argentina y Chile, a partir de sus arraigadas concepciones en la regulación de los cementerios públicos, que ilustran las perspectivas normativas asentadas en América Latina.

Todo ello posibilitará contrastar y determinar las principales tendencias seguidas por ordenamientos pertenecientes al sistema de derecho latino o romano francés. El análisis se enfoca a partir de tres parámetros fundamentales: en cuanto a los sujetos que intervienen en la relación jurídica constituida en los cementerios públicos, los tipos de derechos reconocidos sobre bienes cementeriales, y la publicidad de su reconocimiento.

En España, país con un complicado sistema jurídico de normas nacionales, provinciales y municipales engarzadas sobre una misma materia, el cementerio es un servicio municipal de obligación mínima, que las entidades locales tienen la responsabilidad de prestar por sí o asociadas con otras. Se exceptúan las que sean expresamente dispensadas por la autoridad autonómica por resultar imposible o muy difícil su cumplimiento ${ }^{74}$.

73. El IV Convenio de Ginebra, relativo a la protección debida a las personas civiles en tiempo de guerra y Protocolos adicionales. Su artículo 130 establece que las autoridades en cuyo poder estuvieron los internados se ocuparán de que los fallecidos en cautiverio sean enterrados dignamente, si es posible con arreglo a los ritos de la religión a que pertenezcan, y de que sus sepulturas sean respetadas, convenientemente conservadas y marcadas de modo que se las pueda localizar en cualquier momento. Resumen de los Convenios de Ginebra del 12 de agosto de 1949 y de sus Protocolos Adicionales (2012) Folleto, 2da edición, Ginebra: Comité Internacional de la Cruz Roja.

74. En los artículos 47 y 50 del Decreto 2263/1974, de 20 de julio, que aprueba el Reglamento Estatal de Policía Sanitaria Mortuoria, se exige que cada municipio tenga, por lo menos, un cementerio de características adecuadas a la densidad de su población. El emplazamiento de los cementerios de nueva construcción deben alejarse de las zonas pobladas por lo menos 500 metros.
De este modo, los cementerios municipales pueden ser gestionados directamente por corporaciones locales, sociedades que adopten el sistema de empresa mixta o de capital privado ${ }^{75}$.

En los artículos 60 y 61, del Decreto 2263 de 20 de julio de 1974, Reglamento Estatal de Policía Sanitaria Mortuoria, se reconocen los derechos y deberes de las corporaciones locales en la administración de cementerios municipales. Así, se responsabilizan con su cuidado, limpieza y acondicionamiento; además de la distribución y concesión de parcelas y sepulturas. También establecen los derechos y tasas que procedan por la ocupación de terrenos y licencias de obras; y asumen el nombramiento y remoción de empleados. Por último, se encargan de llevar el registro de sepulturas en un libro foliado y sellado. En el segundo de los preceptos, se exige que los cementerios de pueblos con más de diez mil habitantes, cuenten con un reglamento de régimen interior, y un encargado.

Los Reglamentos internos de camposantos españoles, en su generalidad, regulan de forma explícita la naturaleza del derecho que pueden adquirir los particulares. En todos los casos se trata de concesiones de uso por un periodo de tiempo determinado, y en ningún caso se permite que ese periodo exceda de 99 años, de acuerdo a lo dispuesto por el artículo 93 de la Ley 33/2003, de 3 de noviembre, de Patrimonio de las Administraciones Públicas. Las temporalidades mínimas se establecen en 5, 10, 15 y 30 años de duración, todos renovables. Los textos locales consultados no reconocen la existencia de derechos de propiedad, al considerar al cementerio como un bien de dominio público sobre el que no es posible la titularidad demanial de los particulares ${ }^{76}$.

75. El Reglamento de Cementerios del Ayuntamiento de Madrid de 25 de septiembre de 1987, en su artículo 3 dispone que el Ayuntamiento presta los servicios de cementerio de forma directa a través de la Empresa de Servicios Funerarios de Madrid, Sociedad Anónima, y el objeto del Reglamento es la regulación de las condiciones y formas de prestación del servicio de cementerios, así como las relaciones entre la Empresa y los usuarios que aquella genera.

76. El artículo 20 del Reglamento del Ayuntamiento de Madrid de 25 de septiembre de 1987, fija las concesiones de sepulturas por 99 años, al igual que el artículo 27 de la Ordenanza Municipal de Cementerios del Ayuntamiento de Barcelona de 24 de octubre de 1997. La Ordenanza Reguladora de los Servicios Funerarios del Ayuntamiento de Sevilla de 21 de octubre de 2004, en su artículo 22 , hace referencia al tiempo máximo que establece la legislación vigente, sin determinar la duración en años de la concesión. La Ordenanza de Cementerios y Servicios Funerarios Municipales 
Los derechos adquiridos por el particular sobre las sepulturas de un cementerio público devienen en concesiones demaniales de uso privativo de un bien de dominio público, según disponen los artículos 85.3 y 86.3 de la Ley 33/2003, de 3 de noviembre, de Patrimonio de las Administraciones Públicas. Pueden trasmitirse, tanto inter vivos como mortis causa, de acuerdo con los requisitos establecidos en las Ordenanzas municipales. Se dispone a su vez su formalización en documento administrativo, que será título suficiente para su inscripción en el Registro de la Propiedad. Deben otorgarse por un tiempo determinado, siendo el plazo máximo de duración los 75 años, incluidas las prórrogas, salvo que se establezca otro menor en las normas especiales que sean de aplicación ${ }^{77}$.

La Ordenanza de Cementerios del Ayuntamiento de Barcelona, en su Disposición Final, regula la aplicación del principio de confianza legítima. En virtud de aquel, en las concesiones otorgadas a perpetuidad por normativas precedentes, se deben respetar los derechos adquiridos. Por tal razón, no son de aplicación retroactiva las nuevas ordenanzas municipales que fijan un límite a la duración de las concesiones, salvo que concurran unas razones objetivas que así lo justifiquen. No obstante, los titulares del derecho, quedan obligados al pago de las tasas de conservación de cementerios establecidas en la ordenanza fiscal y en caso de incumplimiento se incurrirá en caducidad del derecho.

Otro tanto se comporta la regulación de los cementerios públicos italianos, cuya organización se encabeza por su normativa base, el Decreto No. 285 de 10 de septiembre de 1990 "Regolamento de polizia mortuoria" y otras que la complementan ${ }^{78}$.

del Ayuntamiento de Valencia de 29 de septiembre de 2006, en su artículo 39 las establece por 50 años, y la Ordenanza Municipal de Cementerios del Ayuntamiento de Zaragoza de 23 de diciembre de 2009, en el artículo 24, concede hasta 49 años.

77. Artículos del 20 al 25 del Reglamento del Ayuntamiento de Madrid; artículos del 34 al 57 de la Ordenanza del Ayuntamiento de Barcelona; artículos del 46 al 48 de la Ordenanza del Ayuntamiento de Valencia; artículo 26 de la Ordenanza del Ayuntamiento de Sevilla y los artículos del 27 al 37 de la Ordenanza del Ayuntamiento de Zaragoza. Además el artículo 93.1.2 de la Ley de Patrimonio de las Administraciones Públicas. 78. Decreto del Presidente della Repubblica 10 settember 1990 , No. 295 approvazione del Regolamento di Polizia Mortuoria (Gazzetta Officiale 12 ottobre No. 239 S.O.), complementado por el Decreto del Presidente della Repubblica di luglio 1934, 27, No. 1265 approvazione del testo unico delle leggi sanitarie; Decreto del Presidente della Repubblica 13 febraio 1964, No. 185; Regio Decreto 9 luglio 1939, No. 1238, sull'ordinamento dello stato
Tal como sucede en la regulación española, los cementerios resultan de subordinación municipal; pero con mayor acierto se establece que su mantenimiento, orden y vigilancia, depende del alcalde. En los particulares casos de cementerios que comprenden más de un municipio, su administración es consorcial, correspondiéndole al alcalde de la comunidad donde el cementerio se ubica ${ }^{79}$.

Especial distinción posee en la ordenación cementerial italiana, la figura del coordinador sanitario de la unidad sanitaria local. Este funcionario se encarga de verificar el funcionamiento de los cementerios y propone al alcalde los procedimientos necesarios para asegurar el cumplimiento del servicio funerario ${ }^{80}$. Sin embargo, no puede obviarse el hecho de que, en el contexto político italiano de la última década, se han suscitado múltiples escándalos por los altos niveles de corrupción.

Como consecuencia, se han adoptado medidas administrativas que trascienden al ámbito de los cementerios. En particular, el artículo 9 de la Ley 183 de 12 de noviembre de 2011 "Disposiciones para la formación del balance anual y plurianual del Estado", legitima un sistema libre de los servicios públicos de relevancia económica a través de la plena concurrencia del mercado. Estos servicios, son nuevamente tratados en el Decreto-Ley No.1/2012 de 24 de enero de 2012, cuya regulación promueve la liberación estatal. Su instrumentación coadyuva la intervención de corporaciones privadas en la administración de cementerios públicos ${ }^{81}$.

civile; Convenzione internazionale di Berlino 10 febbraio 1937 aprobata e resa esecutiva in Italia con Regio Decreto 10 luglio 1937, No. 1379; Decreto del Presidente della Repubblica 10 settembre 1982, No. 915

79. Artículos 49.3 y 51.1 Decreto del Presidente della Repubblica 10 settember 1990, No. 295 approvazione del Regolamento di Polizia Mortuoria (Gazzetta Officiale 12 ottobre No. 239 S.O.)

80. Artículo 51.2 Ídem.

81. MARINI, F (2018) Corrupción en Italia: El antes y el después de la Reforma Severino en Revista Internacional Transparencia e Integridad, Núm. 7, mayo-agosto, recuperado de; https://revistainternacionaltransparencia.org/wp content/uploads/2018/09/fernando-marini.pdf (Consultado: 2/11/2018). Palomba, M. (2012) Il decreto - legge 24 gennaio 2012, n. 1 c.d. "Cresci- Italia" - Le principali novità introdotte nel settore, recuperado de http://www.piscino.it/file/leggi/ liberalizzazioni-07.pdf (Consultado: 2/11/2018). FONDERICO, F. (2003) Ligiene Pubblica, en AAVV Trattato di Diritto Amministrativo, a cura di Sabino CASSESE, Milano: Dott. A Giuffrè-Editore, pp. 770-777. 
Con mayor precisión que la regulación española, el artículo 337 del Texto Único de la Ley Sanitaria, aprobado por el Decreto No. 1265 de 27 de julio de 1934, reconoce que cada comunidad debe poseer un cementerio con al menos un Departamento del sistema de entierro. A su vez, cada cementerio debe prestar obligatoriamente ciertos servicios: el agua potable y los servicios higiénicos para el público y el personal empleado; el cuarto mortuorio, el cuarto para las autopsias y los osarios comunes ${ }^{82}$.

Con similar acierto que en las normas españolas, se reconoce el uso privado de áreas del cementerio, otorgadas mediante concesión a favor de personas naturales o jurídicas. Una vez otorgadas, se establece un tiempo determinado para la construcción de la sepultura, y reconoce el derecho de los concesionarios para determinar quienes pueden ser inhumanos en ellas, ya sean familiares o allegados. Con todo, retrocede este ordenamiento, pues al prohibir su utilización con el propósito de obtener ganancia o especulación, limita la trasmisión inter vivos del derecho de uso, bajo cualquier título o forma ${ }^{83}$.

En equivalencia, las concesiones cementeriales pueden otorgarse por un tiempo determinado, cuya temporalidad mínima supera a la implementada en la regulación española, al establecerla en 10, 30, 50 y 90 años de vigencia. Su duración máxima se fija en 99 años, excepto en los casos de renovación. Por tal razón, las concesiones de tiempo determinado que eventualmente se excedían de este término a la entrada en vigor del anterior y derogado Decreto No. 803 del Presidente de la República del 21 de octubre de 1975, pueden revocarse. Ello sucede al transcurso de 50 años de la última inhumación, o ante la insuficiencia del cementerio de ampliarse, ni construirse uno nuevo ${ }^{84}$.

Coincide la norma rectora italiana del servicio cementerial con las disposiciones españolas, cuando faculta a las localidades para implementar sus propios Reglamentos Comunales de Policía Mortuoria. Se distingue este ordenamiento del español, al concebir a la concesión cementerial

82. Artículos 60, 64 y 67 Decreto del Presidente della Repubblica 10 settember 1990, No. 295 approvazione del Regolamento di Polizia Mortuoria.

83. Artículos 90.1, 92.2.3.4 y 93.1.2 Ídem.

84. Artículo 92.1.2.3.4 Ídem. como la provisión administrativa con que la comunidad concede a uno o más personas, el uso por un tiempo determinado de un área demanial, o de un bien edificado dentro del cementerio, que una vez finalizado se devuelve su uso a la comunidad. Esta provisión administrativa reconoce el derecho de uso de los concesionarios, que alcanza a familiares hasta el sexto grado de consanguinidad y allegados convivientes.

Además, el usuario del servicio cementerial queda obligado al mantenimiento de las sepulturas edificadas para la ejecución de trabajos de restauración o por motivos de decoro, seguridad o higiene. Los bienes incorporados a la concesión, una vez extinguida, no constituyen objeto de propiedad de la persona cuyo derecho se extinguió, traspasándose su dominio a la Administración concedente. Finalmente, legitima la concesión cementerial mediante escritura del contrato, a través del modelo contractual aprobado por la comunidad para cada tipología de concesión, susceptible de inscripción en el Registro de la Propiedad ${ }^{85}$.

Siguiendo la tendencia de los sistemas anteriores, en Francia la gestión de los cementerios se considera un servicio básico de los municipios. La base de la administración territorial francesa, se constituye por los 36680 municipios, contando así con el mayor número de municipios de la Unión Europea (casi el 40 \% de su totalidad). Desde su creación, en 1978, estos son responsables de las normativas, los planes urbanos y de desarrollo también en la esfera

85. Artículos 48.1.2.3.4.5.6, 53 y 54 Regolamento di Polizia Mortuaria del Comune di Bari, approvato dal Consiglio Comunale con delibera No. 0057 del 16 ottobre 2015, recuperado de: https://www.comune.bari.it/ documents/20181/429998/ Reg. +Polizia + Mortuaria ++ C.C. + n $+57+$ del+16.10.2015. $p d f / 7 b 852 e 96-b 348-4 c b b-9 d d 8$ 3130e464e215 (Consultado: 2/11/2018); Artículos 42.5.6.7.8; 45 y 47 Regolamento di Polizia Mortuaria del Comune della Regione Valle d'Aosta, approvato con deliberazione del Consiglio Comunale N. 40 del 9 marzo 2000, recuperado de: http://www.comune.aosta.it/ userfiles/ file/comune/reg_pmort.pdf (Consultado 2/11/2018); Artículos 61, 66, 67, 74 y 78 Regolamento di Polizia Mortuaria del Comune di Conegliano, in vigore dal 07/11/2017, recuperado de: http://www.veritasconegliano.com/PUBBLICA/ARCHIVIO/ Regolamento\%20cimiteri\%2007 11 2017.pdf (Consultado 2/11/2018); Artículos 56, 57 y 58 Regolamento di Polizia Mortuoria del Comune di Foggia, approvato con deliberzione del Consiglio Comunale No. 61 del 23/01/2017, recuperado de: https://www.pfcfoggia.it/wpcontent/uploads/2017/10/ Regolamento_polizia_mortuaria_2017.pdf (Consultado: 2/11/2018) Artículos 42, 43 y 47 del Regolamento di Polizia Mortuoria del Comune di Nettuno, recuperado de: http://www. tuttosuicimiteri.it/wp-content/files/ Nettuno regolamento di Polizia Mortuaria.pdf (Consultado: 2/11/2018). 
funeraria. Como agente estatal, los municipios organizan y mantienen los registros públicos, entre ellos el registro de defunciones y los propios del cementerio. De esta forma, los camposantos franceses se conciben como infraestructuras públicas poseídas por las municipalidades ${ }^{86}$.

La dirección del camposanto no puede delegarse a otro público o a instituciones privadas: el alcalde es, en cualquier caso, el responsable de los ubicados en el territorio municipal. Aunque algunos se manejan bajo los regímenes intermunicipales, las mismas reglas de subordinación se aplican a todos los casos. Las necrópolis francesas, si bien encausan su actividad bajo el mismo derrotero normativo, se han mantenido a merced del municipio. Estas facultades le son atribuidas mediante el Code Général des Collectivités Territoriales ${ }^{87}$.

En este contexto, el país experimenta una creciente oleada de concesiones cementeriales debido al aumento de demandas marcadas por el envejecimiento poblacional. Además, su oferta es relativamente inflexible, debido a las exigencias legales. Las grandes ciudades galas enfrentan dificultades presupuestarias, solventadas con los impuestos concesionales. Estas tendencias coadyuvan el alto grado de complejidad de los precios que son determinados según los rasgos de las concesiones, los cementerios, y las ciudades con sus propios modelos. Tal situación repercute en los precios de las concesiones y los costos de dirección. Por consiguiente, su situación y conveniencias varían de una ciudad a otra, e incluso, de un cementerio a otro en el mismo territorio ${ }^{88}$.

Al igual que en el sistema italiano, y con mayor precisión que el español, el mantenimiento del orden y la decencia en los cementerios se somete al poder de policía del alcalde, como su máximo representante. Dotado de personalidad jurídica y autonomía financiera, este regidor posee poderes

86. KoŁodZIEJSKI, M. (2012) Situación económica, social y territorial de Francia, Bruselas: Departamento Temático B: Políticas Estructurales y de Cohesión, Parlamento Europeo, pp. 13-14.

87. Code général des collectivités territoriales. Dernière modification le 07 octobre 2018 - Document généré le 01 novembre 2018, recuperado de: https://aida.ineris.fr/sites/ default/files/gesdoc/68631/code collectivites territoriales.pdf (Consultado: 2/11/2018).

88. CHANNAC, F., B. FAYE, B. (2016) A hedonistic approach of the burial plot value in the French cemeteries, Bordeaux: INSEEC Business School, pp. 5-11. estatales para la explotación de los servicios de interés público y carácter administrativo, entre ellos, el correspondiente al cementerio ${ }^{89}$. Por su parte, el Code Général des Collectivités Territoriales, en su artículo L2223-1, acentúa con carácter especial la obligación de los municipios de prever, dentro del recinto cementerial, un área comunal para el entierro libre de pobres y otras personas con derecho a ello.

Por otro lado, como reconocen los ordenamientos hasta aquí estudiados, el artículo L2223-13 de la citada norma, faculta a los municipios para conceder parcelas cementeriales a personas naturales. A estos destinatarios de la concesión se les reserva el derecho de construir bóvedas, monumentos y tumbas. El alcalde reglamenta las medidas máximas de estas construcciones. Sin embargo, este ordenamiento, de singular manera, en el artículo L2223-14 reconoce además de las concesiones temporales concedidas por períodos de 15, 30 y 50 años, las concesiones perpetuas. Estas últimas se encuentran en creciente auge al posibilitar el artículo L222316 la conversión a ellas de las temporales.

El régimen francés de concesiones, supera al regulado en los sistemas españoles e italiano, al configurarse a través de normas específicas ${ }^{90}$ que rigen sobre todo el territorio. Otorgadas mediante decreto municipal, las concesiones cementeriales poseen una naturaleza contractual, reconociendo derechos y obligaciones entre Administración y administrado. Se reconocen tres categorías de concesiones: la individual, cuando sólo puede usarse por el concesionario, con exclusión de otros. La colectiva, cuando se constituyen una comunidad de concesionarios, generando la indivisión del único acto de concesión. La doméstica, cuando el concesionario permite el uso del cónyuge, familiares y otras personas con vínculos afectivos ${ }^{91}$.

89. Artículos L2213-9 y L2221-10, Ídem

90. Entre estas normas destacan, entre otras: Ordenanza No. 855 de 28 de julio de 2005, relativa las operaciones funerarias. Artículos 225-17 y 225-18 del Código Penal. Circular del 14 de diciembre de 2009, acerca del ámbito laboral de la Ley No. 1350 del 19 de diciembre de 2008 relativa a la legislación fúnebre. Decreto No. 121 del 28 de enero de 2011 sobre la aplicación de la Ley del 19 de diciembre de 2008.Concessions Funéraires, recuperado de: https://www.caissedesdepotsdesterritoires.fr/ cs/BlobServer? blobkey=id\&blobnocache $=$ true\&blobwhere $=125$ $0170649007 \&$ blobheader=application $\% 2 F p d f \&$ blobcol=urldata \&blobtable=MungoBlobs (Consultado: $2 / 11 / 2018$ )

91. Artículos del L.2223-13 al L.2223-18 del Código General de las Colectividades Territoriales. 
Al fundarse el criterio francés del carácter demanial de la sepultura, destaca este régimen sobre el italiano, sin alcanzar al español. Ello se debe a que al reconocer a las concesiones cementeriales sólo trasmisibles mediante donación o actos sucesorios, sesga la posibilidad de su enajenación por compraventa. Además, para que alcance validez esa trasmisión, debe efectuarse ante notario público, e inscribirse en el Registro de la Propiedad. Una vez formalizado, se realiza la renovación administrativa de la concesión, en la que el alcalde no puede negarse a la constitución de la concesión trasmitida ${ }^{92}$.

En el contexto latinoamericano, México, a tono con las influencias europeas, define a los panteones y cementerios como parte del servicio público a cargo de los municipios. Así lo refiere, conforme a lo establecido en el inciso e) fracción III del artículo 115 de la Constitución Política de los Estados Unidos Mexicanos ${ }^{93}$. A partir de esta disposición, se instrumenta la gestión del servicio de cementerios, de forma prioritaria e ineludible por los Gobiernos Municipales. En tal sentido, cada municipalidad orienta su propio Reglamento de Cementerios para la organización, administración y conservación de los cementerios ubicados en su localidad. Con ello, se definen los deberes del Ayuntamiento en esta materia, concretándose el marco jurídico del servicio cementerial ${ }^{94}$.

Sin embargo, si bien el servicio de cementerio para este ordenamiento posee una esencia pública, se restringe a las tendencias españolas, al liberalizar la gestión privada de cementerios. De esta forma, concesiona además, los servicios funerarios que comprenden desde el fallecimiento, hasta el acto del sepelio, incluyendo los rituales funerarios, suministro de féretros $\mathrm{y}$ otros elementos accesorios propios de la actividad y velatorios. Para ello, estas empresas privadas cuentan con locales habilitados al efecto.

92. Artículo 931 de Code Civil. De la forme des donations entre vifs, recuperado de: http://www.legifrance. gouv.fr/citoyen/ code.ow (Consultado 2/11/2018).

93. Constitución Política de los Estados Unidos Mexicanos. Constitución publicada en el Diario Oficial de la Federación (DOF) el 5 de febrero de 1917. Última reforma publicada DOF el 26 de febrero de 2013, recuperado de: http://www.diputados. gob.mx/ LeyesBiblio/pdf/1_07jul14.pdf (Consultado: 2/11/2018).

94. Así se expresa en la Exposición de los Motivos del Reglamento de Cementerios del Ayuntamiento Constitucional de El Oro, recuperado de: http://eloromexico.gob. $m x /$ transparencia/ marco\%20normativo /REGLAMENTO\%20DE\%20 CEMENTERIOS.pdf (Consultado: 2/11/2018).
Son entonces, los reglamentos municipales, quienes instrumentan la naturaleza y extensión del derecho reconocido a estos entes privados ${ }^{95}$.

Los textos locales consultados ${ }^{96}$ reconocen a los cementerios como bienes de servicio público pertenecientes al Ayuntamiento, sometidos a su administración, cuidado y dirección. Sin embargo, a diferencia de los sistemas jurídicos analizados, se aprecia una indefinición de regímenes público y privado de cementerios. Esta situación se suscita ante la posibilidad de concesionar la operación del servicio público de cementerios, tanto en establecimientos públicos, como privados. De esta forma, los cementerios particulares o privados, también son considerados concesiones municipales otorgadas mediante acuerdo de Cabildo.

Estos camposantos son gestionados por personas naturales o jurídicas (morales), a los que se les autoriza la venta de lotes y el mantenimiento de sus instalaciones. Aún así son incompetentes para efectuar actos que atañen exclusivamente a las autoridades municipales, tales como las inscripciones en Registros Públicos. Por lo tanto, devienen en simples fraccionamientos del cementerio municipal, aptos para efectuar actos de inhumación y exhumación de cadáveres, implementando los requisitos de los sujetos del derecho funerario. El uso de estas dependencias cementeriales se revierte a la municipalidad una vez vencido el plazo de la concesión otorgada (15-30 años) ${ }^{97}$.

95. Así lo reconoce el artículo 84 de la Ley No. 7 de 2 de abril de 1985, Bases del Régimen Local, en relación al artículo 22 del Real Decreto Ley No. 7 de 7 de junio 1996, que liberaliza los servicios funerarios. Tal como referencia los artículos 1 y 2 inciso de la Ordenanza Reguladora de los Requisitos para la Prestación de Servicios Públicos Funerarios en el municipio de Guadalajara. BOP Guadalajara 1998-01-17.

96. Reglamento de Cementerios Municipales para el Municipio de Bolaños, Jalisco, recuperado de: http://www.inafed.gob.mx/ work/paginas municipales/14019 bolanos/Articulo\%208/ II.\%20Informacion\%20sobre\%20el\%20marco\%20juridico\%20 aplicable\%20al\%20y\%20por\%20el\%20sujeto\%20obligado/d/ reglamentos\%20municipales/REGLAMENTO\%20DE\%20 CEMENTERIOS\%20MUNICIPALES.pdf (Consultado: 2/11/2018); El Reglamento de Cementerios del Ayuntamiento Constitucional de El Oro, cit; Reglamento Municipal de Panteones de Fresnillo, recuperado de: http://ordenjuridico.gob. $m x /$ Estatal/ ZACATECAS/Municipios/Fresnillo/FRESREG04.pdf(Consultado: 2/11/2018); Reglamento de régimen interior de los Cementerios Municipales de Güeñes, recuperado de: http://www.guenes. eus/es-ES/Ayuntamiento/OOrdenanzas-Reglamentos/ OrdenanzasReglamentos/02-cementerios.pdf (Consultado 2/11/2018); Reglamento de Cementerios del Distrito Federal, publicado en el Diario Oficial de la Federación, de 28 de diciembre de 1984, recuperado de: http://www.ordenjuridico. gob.mx/Documentos/Estatal/Distrito\%20Federal/ wo27567. pdf(Consultado: 2/11/2018).

97. Artículos 20 y 21 del Reglamento Cementerios Municipales para el Municipio de Bolaños, Jalisco, ob.cit. Artículos $7 . I I$ y 9 del 
En este contexto, destaca la regulación del Reglamento Municipal de Cementerios de la localidad de Güeñes. A contracorriente, su normativa reconoce el estricto y exclusivo sometimiento de todos sus cementerios a la administración, cuidado y dirección de la Corporación municipal, sin perjuicio de las facultades que correspondan a la Autoridad Judicial y Sanitaria. Así se reserva, entre otras funciones, el acondicionamiento de los cementerios, las construcciones funerarias, los servicios e instalaciones; el otorgamiento de las concesiones sepulcrales y reconocimiento de los derechos de cualquier clase; y la percepción de los derechos y tasas establecidas por la ocupación de terrenos, licencias de obras y concesiones cementeriales ${ }^{98}$.

En detrimento de las bases europeas asentadas, la confusión existente en el régimen mexicano de los cementerios públicos y privados, conlleva a un amplio marco regulatorio de las sepulturas. Se aprecia así, dentro del propio contexto nacional, una distancia entre aquellos sistemas normativos que reconocen un derecho exclusivamente concesional, de otras que instrumentan un derecho de propiedad sobre las concesiones a perpetuidad. En ningún caso se reconoce la posibilidad de inscripción registral de los derechos otorgados, cuya ausencia sugiere su nulo tratamiento en este sistema jurídico.

Tal es así que, por un lado, el Reglamento de Cementerios de Bolaños reconoce el derecho de toda familia a adquirir a perpetuidad, un terreno o cripta de los panteones municipales en servicio. Reconocido a través de un título de propiedad, otorga un derecho intransferible, inembargable, e imprescriptible. Sólo podrá ser trasmitido al fallecimiento del titular, a favor de familiares dentro del cuarto grado de consanguinidad ${ }^{99}$. Por el otro, el Reglamento de Cementerios de El Oro, si bien considera al derecho sobre sepulturas como intransferible, inembargable e imprescriptible, no acepta la perpetuidad en las concesiones,

Reglamento de Cementerios del Ayuntamiento Constitucional de El Oro, ob.cit. Artículos 16 y 17 del Reglamento Municipal de Panteones de Fresnillo, ob.cit. Artículos 7.II y 16 del Reglamento de Cementerios del Distrito Federal, ob.cit.

98. Artículos 1 y 2 del Reglamento de régimen interior de los Cementerios Municipales de Güeñes, cit.

99. Artículos 59 y 60 del Reglamento Cementerios Municipales para el Municipio de Bolaños, Jalisco. concediéndola sólo por 7 años, prorrogables por única vez por término idéntico ${ }^{100}$.

Otro tanto resulta del Reglamento de Cementerios de Fresnillo, donde las concesiones a perpetuidad se denominan "concesiones por tiempo indefinido", renovables perpetuamente al término de 7 años ${ }^{101}$. Por su parte, el Reglamento de Cementerios de Güeñes extingue las concesiones a perpetuidad en los casos que no pueda acreditarse su titularidad, y se reconocen por un único término de 75 años. Además, concede derecho para el inmediato depósito de un cadáver por un plazo de 10 a 30 años, transmisible por donación o actos sucesorios, entre familiares y dentro del cuarto grado de consanguinidad, previo abono de la tasa correspondiente ${ }^{102}$.

Por último, el Reglamento del Distrito Federal de México utiliza el término cementerios oficiales, muy abarcador en cuanto al derecho de uso que concede, destinando su Capítulo VIII a las fosas, gavetas, criptas y nichos. Dispone para cada uno de estos bienes cementeriales el término en que se podrá ser titular del derecho de uso. Así, en el caso de las fosas, se proporcionará mediante los sistemas de temporalidades mínima y máxima, entendiéndose por mínima el ejercicio de este derecho por 7 años, a cuyo término retorna al dominio pleno del Departamento del Distrito Federal ${ }^{103}$.

Desde otra óptica, la realidad argentina, con mayor incidencia que en las administraciones anteriormente abordadas y el resto de América Latina, muestra la privatización de casi la totalidad de los servicios públicos. Esta operación privatizadora comprende todas aquellas empresas que no cumplían funciones esenciales o indelegables del Estado. Abarca desde empresas que tenían por objeto meras actividades comerciales o industriales, las reguladas por el Derecho administrativo en virtud del interés público, hasta los servicios públicos tradicionales. Este proceso condujo a que
100. Artículos del 36 al 44 del Reglamento de Cementerios del Ayuntamiento Constitucional de El Oro.

101. Artículos del 53 al 55 del Reglamento Municipal de Panteones de Fresnillo.

102. Artículos 22, 31 y Disposición Transitoria del Reglamento de los Cementerios Municipales de Güeñes.

103. Artículos 59, 61 y 62 del Reglamento de Cementerios del Distrito Federal. 
un variado universo de empresas fue declarado por ley, sujeto a privatización ${ }^{104}$.

Esta situación también alcanzó a los servicios del cementerio, cuyo antiguo paradigma deviene en nuevas formas de relación productiva y económica de la tierra urbana y rural. El nuevo fenómeno de privatización de áreas periféricas permite el auge y consolidación en la práctica social de los cementerios-parques privados. En los últimos años, su irrupción es muestra de un rentable negocio inmobiliario en el cual, cementerios y funerarias trabajan en conjunto, siendo regidas sus preocupaciones por las lógicas de los grandes negocios del mercado. Las necrópolis cambiaron su cariz espiritual por uno comercial, cuyos argumentos de venta reflejan los valores imperantes en la sociedad general: privatización, modernidad, eficiencia y regreso a la naturaleza ${ }^{105}$.

En materia de regulación de cementerios, el territorio argentino al igual que el mexicano, carece de una norma nacional. Son los municipios quienes por mandato constitucional ${ }^{106}$, y a través de sus disposiciones (Ordenanzas), establecen el marco regulador para cada localidad en específico. Conforme al artículo 5 en relación con el 123 de la Carta Magna argentina, cada provincia dicta su propia constitución, asegurando la autonomía municipal y reglando su alcance y contenido en el orden institucional, político, administrativo, económico y financiero. En efecto, en las ordenanzas estudiadas, las municipalidades imponen su jurisdicción en la instalación y administración de cementerios, fundadas en razones higiénicas y de orden público ${ }^{107}$.

104. CASSAGNE, J.C. (2001) Evolución de los principios aplicables a los servicios públicos y problemas actuales tras los procesos de privatización en Argentina, en Revista de Administración Pública, Núm. 154, enero-abril, Madrid, pp. 441-461.

105. FERNÁNDEZ, M.L.; Asís, O.; TURTURRo, C. (2016) Los cementerios territorios de memoria urbana e identidad, VI Jornadas de Investigación - ISBN 978-987-4415-066, Buenos Aires, pp.273-282, recuperado de: https://rdu. unc.edu.ar/bitstream/handle/11086/5753/3.1.\%20 Los\%20cementerios\%20territorios\%20de\% 20memoria. $p d f$ ?sequence $=32 \& i$ Allowed $=y$ (Consultado: 12/6/2018).

106. Constitución Nacional de la República Argentina, aprobada por la Convención Nacional Constituyente de la ciudad de Santa Fe, el 22 de agosto de 1994, recuperado de: http://www. georgetown.edu/pdba/Constitutions/Argentina/argen94.html (Consultado: $12 / 6 / 2018$ )

107. Artículo 1 de la Ordenanza de la Municipalidad de la ciudad de Santiago del Estero No. 838 de 23 de junio de 1983, “Código de Cementerios"; Artículo 1 de la Ordenanza de la Municipalidad de la ciudad de San Miguel de Tucumán No. 3306/03; Artículo 1 de la Ordenanza de la Municipalidad de la ciudad Lomas de Zamora
Se reconocen a su vez, los deberes y atribuciones de las direcciones de cementerios municipales, responsabilizándose con el cumplimiento de sus obligaciones administrativas, limpieza, control de trabajos, inspección de obras. Además inspeccionan los monumentos, a efectos de verificar el cumplimiento de las normas vigentes o cuando las necesidades del servicio así lo requieran. Asimismo, poseen a su cargo el Registro de Concesiones y Transferencias de la Administración, conformado por el Registro Gráfico, con la planimetría de las manzanas y lotes; y el Registro Escrito sobre concesiones y/o transferencias de terrenos ${ }^{108}$.

Tal como sucede en el régimen mexicano, la regulación propia de cada municipalidad hace que varíe entre una y otra la amplitud de los derechos concedidos sobre sepulturas. De este modo, para la municipalidad de Santiago del Estero, la concesión de terrenos se efectúa por 40 años, contados a partir de la fecha del decreto de adjudicación. Además, los derechos sobre las concesiones son intransferibles, ya sea a título oneroso o gratuito, salvo las transferencias por fallecimiento, o las que de sus partes indivisas hagan los herederos entre sí. Subsiste un régimen concesional a perpetuidad no declarado, al otorgar una nueva concesión, dentro del transcurso de su vencimiento, por otros 40 años sucesivos ${ }^{109}$.

Desde otra práctica, la municipalidad de San Miguel de Tucumán instrumenta concesiones de terrenos por el término de 5 años. Igualmente pueden renovarse y transferirse, autorizando las cesiones gratuitas y onerosas, ya sean inter visos o mortis causa, de la totalidad o parte de la concesión del terreno, mausoleo, capilla, sotanito o panteón. No obstante, permanece la posición pública sobre los nichos en los cementerios. Estos se constituyen intransferibles, y cuando

No. 545 de 27 de junio de 1915, modificada por las Ordenanzas No. 1419 de 7 de enero de 1949, No. 1546 de 19 de septiembre de 1952, No. 4200 de 14 de septiembre de 1984, No. 7045 de 14 de diciembre de 1993, No. 9896 de 28 de junio de 2001, y No. 11380 de 6 de diciembre de 2006.

108. Artículo 13; 50-54; 56 c) y g) de la Ordenanza de la Municipalidad de la ciudad de Santiago del Estero; Artículos 34 b); 36; 56 y 85 de la Ordenanza de la Municipalidad de la ciudad de San Miguel de Tucumán; Artículos 3 y 4 de la Ordenanza No. 4200 de 14 de septiembre de 1984 y Artículo 59 de la Ordenanza No. 545 de 27 de junio de 1915, ambos de la ciudad Lomas de Zamora. 109. Artículos 9, 15 y 17 de la Ordenanza de la Municipalidad de la ciudad de Santiago del Estero. 
se desocupen, haya o no terminado el periodo concedido, pasarán automáticamente al poder de la municipalidad. Todo ello sin derecho a reclamo o indemnización por ningún concepto ${ }^{110}$.

Se suma a su vez las posturas adoptadas por la municipalidad de Lomas de Zamora, para la que, paradójicamente, aunque posibilita la enajenación de sepulturas de 5 en 5 años cíclicamente, dispone la abolición de la venta a perpetuidad de dichas sepulturas. Sin embargo, reconoce el régimen de perpetuidad a los terrenos de las secciones destinadas exclusivamente para panteones 0 monumentos, y los nichos construidos alrededor de las paredes del Cementerio. Para ello regula que las concesiones serán renovables, caducando por el nuevo transcurso del término y volviendo a ser propiedad de la Municipalidad que no se reclamen en los 60 días siguientes a su expiración ${ }^{111}$.

Afiliándose a los criterios de las regulaciones europeas, la ordenación de cementerios chilenos, reconoce la autoridad gubernamental para regular los públicos; en tanto consiente la creación de privados $^{112}$. A pesar del claro destino de servicio público que desarrollan tanto los cementerios sujetos a instituciones del Estado, como los de propiedad del Servicio Nacional de Salud y de las municipalidades, no existe un reconocimiento normativo expreso de esta condición. Sólo algunos Reglamentos de cementerios municipales la refieren ${ }^{113}$.

De este modo, las normas vigentes en materia de cementerios e inhumaciones, se enmarcan

110. Artículos 4 y 25 de la Ordenanza de la Municipalidad de la ciudad de San Miguel de Tucumán.

111. Artículos 28 y 32 de la Ordenanza No. 545 de 27 de junio de 1915, ambos de la ciudad Lomas de Zamora.

112. Así lo referencian SERRANo, S. (2009): ¿Qué hacer con Dios en la República? Política y secularización en Chile (18451885), Santiago de Chile: Fondo de Cultura Económica, p. 222; IRARRÁZAVAL, A. Hacia un nuevo consenso en la regulación de los cementerios...cit., pp. 33-56.

113. Resolución No. 6l-G.G./2017 de la municipalidad de Valparaíso, de 25 de abril de 2017 "Reglamento de los Cementerios № 1, 2 y 3 de Valparaíso administrados por la Corporación Municipal de Valparaíso para el Desarrollo Social" en su artículo 2 dispone que por la característica de servicio de utilidad pública que el Cementerio presta a la comunidad, este reglamento contiene las normas a las cuales deben ceñirse los Titulares de sepulturas, sus herederos y cesionarios, o propietarios a cualquier título y en general todas las personas que ingresen al recinto. en el Código Civil ${ }^{114}$, el Código Sanitario ${ }^{115}$ y el Reglamento General de Cementerios ${ }^{116}$. Este enramado supera a las regulaciones mexicana $\mathrm{y}$ argentina, al mantener postura a tono con la regulación francesa, configurando un sistema uniforme con alcance nacional. En este sentido, el Código Civil chileno, en su artículo 587 dispone que el uso y goce de las capillas y cementerios, situados en posesiones de particulares y accesorios a ellas, pasarán a las personas que sucesivamente adquieran las posesiones en que están situados, a menos de disponerse otra cosa por testamento o por acto entre vivos.

Por su parte, el Código Sanitario, reconoce al Servicio Nacional de Salud como el único ente estatal que autoriza la instalación y funcionamiento de cementerios. Estipula la obligación de las municipalidades de establecer cementerios en los lugares en que no los hubiere o fueren insuficientes. Además dispone la implementación de un Reglamento que regirá para la instalación y funcionamiento de todos los cementerios. En consecuencia, se promulga el Reglamento General de Cementerios ${ }^{117}$.

En este sentido, el Reglamento General de Cementerios regula dos clases de cementerios. De un lado, los generales o públicos, que pertenecen a alguna institución del Estado, ya sean propiedad del Servicio Nacional de Salud o de las municipalidades. De otro, los particulares de determinados cultos religiosos; los de colonias extranjeras; los de indígenas, entre otros. Con independencia a su clase todo cementerio estará a cargo de un Director o Administrador, que responderá ante la autoridad sanitaria. Sus

114. Código Civil de Chile, actualizado al año 2000, vigente desde el 1 de enero de 1857, recuperado de: https://www.google.com/

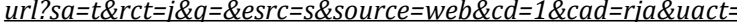
8\&ved=2ahUKEwj31sT3eTiAhWHtlkKHRoDAxYQFjAAegQIAxAC \&url=http $\% 3 A \% 2 F \% 2 F$ www.acnur.org\%2Ffileadmin $\% 2 F D o c u$ mentos\%2FBDL\%2F2002\%2F1803.pdf\&usg =AOvVaw $1 D n Q Y N g$ kqa3mK 9cWdhIfX (Consultado: 22/5/2018)

115. Decreto con Fuerza de Ley No. 725 de 11 de diciembre de 1967, vigente desde el 31 de enero de 1968, modificado hasta el 13 de septiembre de 2011 mediante Ley 20533 de la propia fecha, recuperado de http://www.leychile.cl/N?i=5595\&f=201109-13\&p= (Consultado: $11 / 12 / 2018)$.

116. Decreto No. 357 de 15 de mayo de 1970, vigente desde el 18 de junio de 1970, modificado hasta el 8 de febrero de 2006 mediante Decreto 4 de la propia fecha, recuperado de http:// www.leychile.cl $/ N$ ? $1=12643 \& f=2006-02-08 \& p=$ (Consultado: 11/12/2018).

117. Artículos 136 y 138 del Código Sanitario de Chile. 
obligaciones se establecen en los Reglamentos internos de los cementerios ${ }^{118}$.

Este Reglamento ordena además, de modo general, las clases de sepulturas constituidas en todo cementerio. De acuerdo a su extensión en el tiempo, éstas pueden ser perpetuas, o temporales a largo o corto plazo. No obstante, cobija derechos civiles y administrativos bajo una misma sombra legislativa. Así, como perpetuos nacen los derechos de los propietarios fundadores de una sepultura de familia y de sus parientes, a ser sepultados en ella. Las sepulturas temporales a largo plazo se otorgan por 20 años, pudiendo renovarse por una sola vez por igual período. Por su parte, las temporales a corto plazo se otorgan por 5 años, renovables por períodos iguales y sucesivos hasta 20 años ${ }^{119}$.

Por otra parte, un estudio de Reglamentos internos de cementerios chilenos demuestra la forma en que el régimen general de cementerios, interviene en la falta de concreción de un sistema definido para las sepulturas. Tal confusión parte de reconocer, por un lado, el carácter general o público del cementerio, obligándose a resguardar áreas para inhumación de indigentes. Por otro, admite la concertación de contratos de arrendamiento (para las sepulturas temporales) y compraventas (para las perpetuas), brindándole a su vez el régimen arancelario de las concesiones municipales. En su configuración, ratifican los plazos que brinda el Reglamento General de Cementerios, sin límites de tiempo a las consideradas perpetuas ${ }^{120}$.

118. Artículos 14 y 15 del Reglamento General de Cementerios. 119. Artículos 29; 32; 33 y 41 Ídem.

120. Se seleccionaron entre los de más reciente promulgación: Artículos 4; 16; 17 y 20 de la Ordenanza No. 003 de Funcionamiento del Parque Cementerio General de Temuco de 28 de julio de 2010, brindan un régimen de propiedad, reconociendo la venta y arrendamiento de la sepultura; sin embargo, el artículo 34 de la propia norma, remite las formas de pago de los servicios y actuaciones administrativas del cementerio, a la Ordenanza Local No. 002 sobre Derechos Municipales por Concesiones, Permisos, Ocupación de Bienes Nacionales de Uso Público, Propaganda y otros Servicios, de 24 de diciembre de 1993, que en los artículos del 26 al 35, les aplica un régimen concesional Artículos 5; 10; 13; 27 y 67 del Decreto Exento No. 61 Reglamento No. 12 de Cementerio de la I. Municipalidad de Nueva Imperia de 18 de diciembre de 2012; Artículos 3; 4; 9 y 10 de la Resolución No. 6l-G.G./2017 de la municipalidad de Valparaíso, de 25 de abril de 2017 "Reglamento de los Cementerios № 1, 2 y 3 de Valparaíso administrados por la Corporación Municipal de Valparaíso para el Desarrollo Social".
De acuerdo a sus postulados, mientras que los derechos sobre sepulturas perpetuas incluyen la posibilidad de inhumar a los cónyuges y parientes legítimos hasta la tercera generación; las temporales se adquieren para el uso individual. La transferencia del derecho de sepultura se efectúa mediante escritura pública, previa autorización del Administrador, y se inscribirá en el Registro de la Propiedad y en el de Transferencias del Cementerio. A partir de la suscripción de los contratos domínicos, los Reglamentos internos se consideran parte integrante de ellos. Así, los contratantes se obligan a cumplir con cada una de sus disposiciones, del mismo modo que se transfieren a quienes los sucedan en sus derechos a cualquier título ${ }^{121}$.

\section{CONCLUSIONES}

De manera general, la existencia de cementerios y lugares enterramientos data desde la antigüedad. Durante el cristianismo, los romanos variaron las costumbres funerarias, al utilizar fosas comunes llamadas catacumbas. La expansión del cristianismo en la Edad Media, resultó en la construcción de iglesias y alrededor de ellas los cementerios. En estos fue sepultada la gente común, mientras que el clérigo y la nobleza se ubicaban en el interior de las iglesias. A partir del siglo XVIII esta costumbre medieval fue criticada, por los malos olores que originaron focos de enfermedades y la saturación de estos espacios. Así, a finales del siglo XVIII se establecieron los cementerios extraurbanos modernos.

Los cementerios antiguos se mantuvieron bajo un manto religioso y mágico, concebidos como cosa fuera del comercio, sobre ellos no podían constituirse derechos privados. Sin embargo, la época medieval concibió el otorgamiento de derechos de propiedad a perpetuidad sobre espacios de enterramiento. El siglo $\mathrm{XX}$ trajo consigo fuertes corrientes doctrinales española, francesa, alemana e italiana, que enmarcaban a los cementerios y sepulturas en el ámbito público o privado del Derecho. Estas influencias impactaron

121. Artículos 3; 11; 12 y 38.3.4 de la Ordenanza No. 003 de Funcionamiento del Parque Cementerio General de Temuco de 28 de julio de 2010; Artículo 10 a); 13; 14.3 .4 y 58.7 de Decreto Exento No. 61 Reglamento No. 12 de Cementerio de la I. Municipalidad de Nueva Imperial de 18 de diciembre de 2012 Artículo 10; 25.3.4; 28 y 58 de Resolución No. 6l-G.G./2017 de la municipalidad de Valparaíso, de 25 de abril de 2017 Reglamento de los Cementerios № 1, 2 y 3 de Valparaíso. 
en América concibiéndose de manera similar a la doctrina europea. No obstante, cada cultura ha aplicado sus propios rituales funerarios y sus formas específicas de concebir los enterramientos.

Mucho se ha debatido sobre la naturaleza jurídica de los cementerios; pero ha sido la doctrina del dominio público la que ha primado en la concepción normativa de los cementerios. Es por ello que, aunque subsisten doctrinas que enmarcan a los derechos sobre sepulturas dentro de la propiedad, se ha impuesto el régimen demanial, cuyos medios de uso privativo resultan el permiso de uso y la concesión de uso (temporal o perpetua). En ambos medios se enmarcan, tanto servidumbres administrativas, como las potestades administrativas protectores del dominio administrativo, moldeando así la amplitud y contenido de estos derechos.

En la relación jurídica cementerial, se identifica como sujeto activo al Estado, y como pasivo a los administrados. Entre ambos sujetos se genera una relación desigual, con fuerte predominio de la Administración, cuya función coadyuva a la defensa del patrimonio demanial. Tiene por objeto el conjunto de bienes demaniales integrados a los cementerios públicos susceptibles de un uso privativo. Estos bienes se componen de cosas corporales, que a su vez se subdividen en bienes muebles e inmuebles. Su elemento causal resulta un acto administrativo, que genera relaciones del usuario con otros particulares regidas por el derecho privado, siempre que no exceda los límites del Derecho Administrativo.

El régimen delos cementerios públicos requiere una regulación administrativa que organice su funcionamiento, y vele por el cumplimiento de los requerimientos administrativos en el uso de los bienes cementeriales. En este sentido y del estudio de los ordenamientos europeos de España, Italia y Francia, se aprecia una superioridad regulatoria en este último, al concebir su ordenación desde normas nacionales, lo que uniforma su tratamiento. En América Latina, y del examen de los sistemas mexicano, argentino y chileno, ha sido en el postrero donde se implementa una ordenación coherente para todas sus municipalidades. 


\section{REFERENCIAS BIBLIOGRÁFICAS}

- ALBI, F. (1960). Tratado de los modos de gestión de las Corporaciones locales, Madrid: Aguilar, p. 650.

- ALESSI, R. (1960). Sistema Istituzionale di Diritto Amministrativo, Milano: Dott. A Giuffrè-Editore, p. 20.

- ALESSI, R. (1970). Instituciones de Derecho Administrativo, Tomo II, Barcelona: Bosch, p. 411.

- SÁNCHEZ MORÓN, M. (1997). Los Bienes Públicos, Madrid: Tecnos, S.A, p. 37.

- ARANGLO RUIZ, V. (1952). Instituciones de Derecho romano, traducido por José M. CARAMÉS PERRO, Buenos Aires: Depalma, p.189.

- ARBUS (1924). Concessions dan cimentières...cit;

- ARIÉS, P. El hombre ante la muerte, Madrid: Taurus Ediciones, p. 12.

- BALDI PAPINI, U. (1956). L'annullamento d'ufficio degli atti amministrativi invalidi, Rist. varitipica dell'ed. del 1939, Milano: Firenze Cya, pp. 56-64.

- BALlesteros, A. (1990). Manual de Bienes de las Entidades Locales, Madrid: Ministerio para las Administraciones Públicas, pp. 23-26.

- BALLESTEROS, L.A. (2006). Los principios de irretroactividad y confianza legítima en el Derecho funerario: el régimen transitorio de los derechos de sepultura en la jurisprudencia, en Revista Española de Derecho Administrativo, Núm. 129, Madrid, pp. 173-197.

- BARRAQUERO, CARETTE, ATTWELL OCANTOS, REQUENA (1912). Diccionario de Legislación Nacional y Provincial, Tomo II, Buenos Aires: Tipográfica Editora Argentina, pp. 295, 298 у 300.

- BARRAQUERO, J. (1889). Cuestiones Jurídicas, 2da edición, Buenos Aires: Tip. Lit. y Enc. del Colegio PIO IX de Artes y Oficios, p. 144.
- BATBIE, A. (1888). Traité théorique et pratique de Droit Public et Administratif, Tome V, Paris: L. Larose et Forcel Libraires-Editeurs, p. 319.

- BERTHÉLEMY, H. (1910). Traité elementaire de Droit Administratif, Paris: Rousseau \& Cie Éditeurs, p. 478, 481-482. - BERTRAND, R. (2005). Que de vertus.... Les épitaphes édifiantes des débuts du XIX e siècle, en BERTRAND R., ANNE C., y JEAN-NOËL P. Les narrations de la mort, Aix-en-Provence: Publications de l'Université de Provence, pp. 241-255.

- BERTRAND, R. (2010). Estudio de los cementerios franceses contemporáneos. Los problemas de método, en Revista Trace, Núm. 58, diciembre, Centro de Estudios Mexicanos y Centroamericanos, México D.F., pp. 71-81.

- BIBILONI, J.A. (1929). Anteproyecto de reformas al Código Civil Argentino, Tomo III, Buenos Aires: Valerio Abeledo, p. 29.

- BIELSA, R. (1956). Derecho administrativo, Tomo III, 5ta Edición, Buenos Aires: Depalma, p. 444.

- CAETANO, M. (1970). Manual de Direito Administrativo, Tomo I, Rio de Janeiro: Companhia Editora Forense, p. 206.

- CASSAGNE, J.C. (2001). Evolución de los principios aplicables a los servicios públicos y problemas actuales tras los procesos de privatización en Argentina, en Revista de Administración Pública, Núm. 154, enero-abril, Madrid, pp. 441-461.

- CIFUENTES, S. (1995). Derechos personalísimos, Buenos Aires: Astrea de A. y R. Depalma, p. 18 y ss.

- Corán, recuperado de http://www. nurelislam.com/coran/index.htm (Consultado: 4/3/2016)

- Cuerpo del Derecho Civil Romano, traducido al castellano del latín por 
KRIEGEL, HERMANN y OSENBRÜGGEN, Tomo III, 2da parte, 1892, Barcelona: Jaime MOLINAS, Editor-Valencia, pp. 134-136.

- CHANNAC, F., B. FAYE, B. (2016) A hedonistic approach of the burial plot value in the French cemeteries, Bordeaux: INSEEC Business School, pp. 5-11.

- CHARLES, H. (1974). Accessoire et domaine public en droit administratif français, en Mélanges Michel Stassinopoulos, Paris: LGDJ, pp. 187-192.

- DIEZ, M.M. (1940). Dominio Público. (Teoría General y Régimen Jurídico), Buenos Aires: Abeledo- Editor, p. 225.

- DUCROCQ, Th. (1900). Cours de Droit Administratif, Tome VI, No.2305, Paris: Ancienne Librairie Thorin et Fils. A. Fontemoings, Éditeurs, pp. 270-272.

- ESCOLA, H.J. (1989). El interés público como fundamento de Derecho Administrativo, Buenos Aires: Ediciones Depalma, p. 201.

- ESCRICHE, J. (1863). Diccionario Razonado de Jurisprudencia y Legislación, Paris: Librería de Rosa y Bouret, p. 431.

- FERNÁNDEZ DE VELASCO CALVO, R. (1935) Naturaleza jurídica de cementerios y sepulturas: historia y problemas jurídicos, Madrid: Revista de derecho privado, p. 91.

- FERNÁNDEZ, M.L.; ASÍS, O.; TURTURRO, C. (2016). Los cementerios territorios de memoria urbana e identidad, VI Jornadas de Investigación - ISBN 978-9874415-06-6, Buenos Aires, pp.273-282, recuperado de: https://rdu.unc.edu.ar/ bitstream/handle/11086/5753/3.1.\%20 L o s \% 20 c e me n t e ri o s \% 20 territorios $\% 20 \mathrm{de} \%$ 20 memoria. pdf? sequence $=32 \&$ is Allowe $d=y$ (Consultado: 12/6/2018).

- FONDERICO, F. (2003). L'igiene Pubblica, en AAVV Trattato di Diritto Amministrativo, a cura di Sabino
CASSESE, Milano: Dott. A Giuffrè-Editore, pp. 770-777.

- GARCÍA DE ENTERRÍA (1997). El dogma de la reversión de concesiones, en GARCÍA DE ENTERRÍA E. y FERNÁNDEZ, T.R. (1997) Curso de Derecho Administrativo, Tomo I, Octava Edición, Madrid: Civitas, p. 564.

- GARCÍA DE ENTERRÍA, E. y FERNÁNDEZ, T. R. (2000). Curso de Derecho Administrativo, Madrid: Civitas, pp. 93-112. PARADA, J. R. (1988). Derecho Administrativo (Bienes públicos y urbanismo), Madrid: Marcial Pons, p. 164.

- BALLESTERos, Manual de Bienes de las Entidades...cit., pp. 28-29.

- GARRIDO FALLA, F. (1986). Tratado de Derecho Administrativo, Volumen II (Parte General: Conclusión), $7 \mathrm{ma}$ edición, Madrid: Centro de Estudios Constitucionales, p. 471.

- GIANNINI M.S. (1991). Derecho Administrativo, trad. Luis ORTEGA, vol. 1ro, Madrid: Ministerio de las Administraciones Públicas, pp. 61-62.

- GONZÁlEZ, A. (1970). El cementerio español de los siglos. XVIII y XIX. Madrid: Archivo Español de Arte. No.171, pp. 289-320.

- GONZÁLEZ, J. (1975). Los derechos reales administrativos, Madrid: Civitas S.A., p. 106.

- GUICCIARDI, E. (1934) Il Demanio, Milano: CEDAM, pp. 153-154.

- GUICCIARDI, E. Il Demanio, cit., pp. 74-75.

- BALLBÉ, M. (1948). Concepto del Dominio Público, Barcelona: Bosch, p. 9.

- CAetano, M. Manual de Direito...cit., p. 178.

- HAURioU, M. (1927). Précis de droit administratif, Paris: Recueil Sirey, pp. 162-188.

- HERNÁNDEZ, R. (2008). Situación Jurídica de los Cementerios Públicos, recuperado de: http://sitios.poderjudicial.go.cr. (Consultado: 5/12/2014). 
- IBLER, M. (2016). Los nuevos retos y tendencias del Derecho administrativo en Alemania, en Revista IUSTA, Núm. 45, Bogotá, pp. 165-182.

- IRARRÁZAVAL, A. (2018). Hacia un nuevo consenso en la regulación de los cementerios: la evolución de las normas civiles y canónicas a lo largo del S. XX, en Revista Chilena de Derecho, vol. 45, Núm. 1, pp. 33-56. DUBIEL, K. (2015). La privación de las exequias eclesiásticas en el Código de Derecho Canónico de 1983, en Revista Civilizar de Ciencias Sociales y Humanas. Núm. 15, pp. 37-46.

- JANSSE, L. (1938). Les traits principaux du régime des biens du domaine public, Paris: Dalloz, pp. 125-126.

- JEMOLO, A.C. (1962). Lezioni di diritto ecclesiastico, Milano: Dott. A GiuffrèEditore, p. 23. ROLLAND, L. (1938) Précis de droit administratif, 7ème édition, Paris: Dalloz , pp. 424 y ss.

- JOURnÈ, M. (1925). Précis de Droit Administratif, Paris: Librairie de la Société du Recueil Sirey, p. 329.

- KEITH-LUCAS, B. y RICHARDS, P.G. (1980). Historia del Régimen Local Inglés en el siglo XX. Colección "Administración y Ciudadano", trad. Joaquín HERNÁNDEZ, Madrid: Instituto de Estudios de Administración Local, p. 51.

- KOŁODZIEJSKI, M. (2012). Situación económica, social y territorial de Francia, Bruselas: Departamento Temático B: Políticas Estructurales y de Cohesión, Parlamento Europeo, pp. 13-14.

- LAFAILlE (1944). Tratado de los Derechos Reales, Tomo II, No. 1016, Buenos Aires: Tipográfica Editora Argentina, p. 161.

- LAUBADÈRE A. (1936). Les concessions dans les cimetières, en Revue du droit public et de la science politique, Paris: Dalloz, pp. 612- 620.

- LAUBADÈRE, A. (1958). Droit Administratif Spécial, Paris: Presses Universitaires de France, p. 738; GARCÍA DE ENTERRÍA E.y FERNÁNDEZ, T.R. Curso de Derecho...cit., p. 48.

- LAZO PREUSS, S. (1930). Régimen legal de las aguas corrientes, Santiago de Chile: La Ilustración, pp. 159-160.

- LE BALLE, R. (1924). De la nature du droit du concessionnaire de sépulture, Paris: Librairie Dalloz, pp. 108-109.

- LEY DE LAS XII TABLAS, recuperado de: https://www.academia.edu/37578109/ LEY_DE_LAS_XII_ TABLAS.pdf (Consultado 23/5/2019).

- LÓPEZ J.A. y SÁNCHEZ, J.L. La concesión administrativa en la esfera local...cit., pp. 320-321.

- MARIEnhoff, M. S. Tratado de Derecho Administrativo, Tomo V, cit., p. 153

- MARINI, F (2018). Corrupción en Italia: El antes y el después de la Reforma Severino en Revista Internacional Transparencia e Integridad, Núm. 7, mayo-agosto, recuperado de; https://revistainterna cionaltransparencia.org/wp-content/ uploads/2018/09/fernando-marini.pdf (Consultado: 2/11/2018).

- MARTÍN-RETORTILLO, S. (1963). Responsabilidad de la Administración pública por lesión de intereses legítimos, en Revista de Administración Pública, Núm. 42, Madrid, pp. 453 y ss.

- MATILlA, A. Fundamentos del régimen jurídico de las concesiones...cit., p. 36.

- MAYER, O. (1951). El derecho administrativo alemán, Tomo III, Parte Especial. El Derecho Público de las cosas, Buenos Aires: Depalma, p. 121.

- MONACELLI, G. (1943). Elementos de Derecho Administrativo y legislación fiscal y aduanera, 3ra edición., Buenos Aires: Librería y Editorial "El Ateneo", p. 11.

- New York Field Codes Series. Volume V. State of New York. The Lawbook Exchange, Ltd.- Clark, New Jersey-Biblio. com, recuperado de: https://www.biblio. 
com/bookstore/the-lawbook-exchangeltdclark\&usg= AOvVaw0T64rKbVlf-ZY7l_ NMsAXH (Consultado: 2/11/2018).

- ORTEGA GARCÍA, E. (2016). El derecho a la sepultura y su contextualización normativa en el ordenamiento jurídico cubano. Tesis en opción al grado académico de Máster en Derecho Constitucional y Administrativo. Universidad de Oriente, Cuba.

- PACELLI, F. (1918). Le acque pubbliche, Terza edizione, Torino: Cedam, pp. 252253 y 293.

- PALOMBA, M. (2012). Il decreto - legge 24 gennaio 2012, n. 1 c.d. "Cresci- Italia" - Le principali novità introdotte nel settore, recuperado de http://www.piscino. it/file/leggi/liberalizzazioni-07.pdf (Consultado: 2/11/2018).

- PARADA, R. (2004). Derecho Administrativo, Tomo I, Parte General, 15ª edición, Madrid: Marcial Pons, p. 347.

- PÉREZ GÁlVEZ, J. F. (1997). El sistema funerario en el Derecho español, Pamplona: Aranzadi, p. 335.

- PRESUTTI, E. (1931). Istituzioni di Diritto Amministrativo Italiano, Volume primo, Milano: Casa Editrice Giuseppe Principatto - Messina, pp. 220-223.

- PROUdhon, M. Traité du Domaine Public...cit., Tome I, pp. 460-462.

- RANELLETTI, O. (1897). Concetto, natura e limiti del demanio pubblico, en Rivista Giurisprudenza Italiana, Torino: Unione Tipografico-Editrice Torinese, p. 374;

- RANELLETTI, O. (1945). Teoria degli atti amministrativi speciali, Settima edizione riveduta e integrata, Milano: Dott. A. Giuffrè - Editore, pp. 129-133.

- RESTA, R. (1942). La revoca degli atti amministrativi, Parte Generale, Milano: Dott. A. Giuffrè - Editore, pp. 63-69.

- Resumen de los Convenios de Ginebra del 12 de agosto de 1949 y de sus Protocolos Adicionales (2012). Folleto, 2da edición, Ginebra: Comité Internacional de la Cruz
Roja.

- REY DON ALFONSO X EL SABIO (1807). Siete Partidas, Madrid: Imprenta Real, pp. 22-23.

- RODRÍGUEZ BLANCO, M. (2015). Régimen jurídico de cementerios y sepulturas, Granada: Comares S. L., p. 49.

- BERThÉlEMY, H. Traité elementaire de Droit...cit., p. 718.

- SALVAT R. (1923). Tratado de Derecho Civil Argentino (Derechos Reales), Tomo 1, No. 1436, Buenos Aires: Tipográfica Editora Argentina, p.751. PÉREZ GÁLVEZ, J. F. (1997). El sistema funerario en el Derecho español, Pamplona: Aranzadi, pp. 335 y ss.

- SÁNCHEZ MORÓN, M. (1997). Los bienes públicos, Madrid: Editorial Tecnos S.A., p. 37.

- Santa Biblia (1998) Versión Reina Valera Revisada en 1960, Estados Unidos de América: Sociedades Bíblicas Unidas, p.171.

- SAYAGUÉS LASO, E. (2010). Tratado de Derecho Administrativo, Tomo II, 9na edición, Montevideo: Fundación de la Cultura Universitara (FCU), p. 78.

- SERRANO, S. (2009). ¿Qué hacer con Dios en la República? Política y secularización en Chile (1845-1885), Santiago de Chile: Fondo de Cultura Económica, p. 222.

- STEDMAN R. (2000). Principales postulados del movimiento judío, Nashville: Editorial Caribe Inc., p. 77.

- TROTABAS, L. (1924). De l'utilisation du domaine public par les particuliers; essai de classification juridique, Paris: Librairie Dalloz, pp. 142-156.

- VEIZAGA, K. (2005). Representación social de la muerte en distintas religiones, La Paz: Editorial Ajayu, p. 12.

- VILLAR PALASÍ, J.L. Concesiones administrativas...cit., p. 756.

- VILLEGAS BASAVILBASO, B. Derecho Administrativo, Tomo IV, cit., p. 403.

- VITALE, A. (1920). Il regime delle acque 
nel diritto pubblico e privato italiano, Milano: Hoepli, p. 362.

- ZANOBINI, G. Curso de Derecho Administrativo, Tomo IV, cit., p. 74.

\section{Normas consultadas.}

- España.

- Ley 33/2003, de 3 de noviembre, de Patrimonio de las Administraciones Públicas.

- Ordenanza de Cementerios y Servicios Funerarios Municipales del Ayuntamiento de Valencia de 29 de septiembre de 2006.

- Ordenanza Municipal de Cementerios del Ayuntamiento de Barcelona de 24 de octubre de 1997.

- Ordenanza Municipal de Cementerios del Ayuntamiento de Zaragoza de 23 de diciembre de 2009.

- Ordenanza Reguladora de los Servicios Funerarios del Ayuntamiento de Sevilla de 21 de octubre de 2004.

- Reglamento de Cementerios del Ayuntamiento de Madrid, de 25 de septiembre de 1987.

- Italia.

- Legge 183 di novembre le 122011 "Disposizioni per la formazione della pianta annua ed equilibrio di multi-anno dello Stato."

- Regio Decreto 9 luglio 1939, No. 1238, sull'ordinamento dello stato civile.

- Convenzione internazionale di Berlino 10 febbraio 1937, aprobata e resa esecutiva in Italia con Regio Decreto 10 luglio 1937, No. 1379.

- Decreto 2263/1974, di luglio 20 che approva la Stato Regolamentazione di Polizia Sanitaria Mortuoria.

- Decreto del Presidente della Repubblica 10 settember 1990, No. 295 approvazione del Regolamento di Polizia Mortuoria (Gazzetta Officiale 12 ottobre No. 239 S.0.)

- Decreto del Presidente della Repubblica 10 settembre 1982, No. 915.
- Decreto del Presidente della Repubblica 13 febraio 1964, No. 185.

- Decreto del Presidente della Repubblica di luglio 1934, 27, No. 1265 approvazione del testo unico delle leggi sanitarie.

- Ordinanza-legge No.1/2012 di gennaio di 2012, 24 di chi regolamentazione promuove la liberazione statale.

- Regolamento di Polizia Mortuaria del Comune della Regione Valle d'Aosta, approvato con deliberazione del Consiglio Comunale N. 40 del 9 marzo 2000, recuperado de: http://www. comune.aosta.it/userfiles/file/comune/ reg_pmort.pdf (Consultado 2/11/2018).

- Regolamento di Polizia Mortuaria del Comune di Bari, approvato dal Consiglio Comunale con delibera No. 0057 del 16 ottobre 2015, recuperado de: https://www.comune.bari.it/ documents/20181/429998/Reg.+ Polizia + Mortuaria ++ C.C. + n. $+57+d$ el+16.10.2015.pdf/7b852 e96-b3484cbb-9dd8 3130 e464e215 (Consultado: 2/11/2018).

- Regolamento di Polizia Mortuaria del Comune di Conegliano, in vigore dal 07/11/2017, recuperado de: http://www.veritasconegliano.com/ PUBBLICA/ARCHIVIO/ Regolamento $\% 20$ cimiteri\%2007_11_2017.pdf (Consultado 2/11/2018).

- Regolamento di Polizia Mortuoria del Comune di Foggia, approvato con deliberzione del Consiglio Comunale No. 61 del 23/01/2017, recuperado de: https://www.pfcfoggia.it/wp-content/ uploads/2017/10/ Regolamento_ polizia_mortuaria_2017.pdf (Consultado: 2/11/2018).

- Regolamento di Polizia Mortuoria del Comune di Nettuno, recuperado de: http:// www.tuttosuicimiteri.it/wp-content/ files/Nettuno_regolamento_di_Polizia_ Mortuaria.pdf (Consultado: 2/11/2018). 
- Francia.

- Code civil. De la forme des donations entre vifs, recuperado de: http://www. legifrance. gouv.fr/citoyen/code.ow (Consultado 2/11/2018).

- Code punissable.

- Codegénéral des collectivitésterritoriales. Dernière modification le 07 octobre 2018 - Document généré le 01 novembre 2018, recuperado de: https://aida.ineris. $\mathrm{fr} /$ sites/default/files/gesdoc/68631/ code_collectivites_ territoriales.pdf (Consultado: 2/11/2018).

- Loi No. 1350 de décembre 19, 2008 sur législation funéraire, installer la vigueur de décembre 142009.

- Décrète No. 121 de janvier 282011 sur l'application de la Loi de décembre 19 2008.

- Ordonnance No. 855 de juillet relatif de 2005, 28 les opérations funéraires.

- Concessions Funéraires, recuperado de: https://www. caissedesdepotsdesterritoires.fr/cs/ Blo bServer?blobkey $=$ id\&blobnocache $=$ true \&blobwhere $=1250170649007 \&$ blobhea der=application $\% 2 \mathrm{Fpdf} \&$ blobcol=urlda ta\&blobtable=MungoBlobs (Consultado: 2/11/2018)

- México.

- Constitución Política de los Estados Unidos Mexicanos. Diario Oficial de la Federación (DOF) el 5 de febrero de 1917. Última reforma publicada DOF el 26 de febrero de 2013, recuperado de: http:// www.diputados. gob.mx/LeyesBiblio/ pdf/1_07jul14.pdf (Consultado: 2/11/2018).

- Ley No. 7 de 2 de abril de 1985, Bases del Régimen Local.

- Real Decreto Ley No. 7 de 7 de junio 1996.

- Reglamento de Cementerios del Ayuntamiento Constitucional de El Oro, recuperado de: http://eloromexico. gob.mx/transparencia/marco\% 20
normativo/REGLAMENT 0\%20DE\%20

CEMENTERIOS.pdf

(Consultado:

2/11/2018).

- Reglamento de Cementerios del Ayuntamiento Constitucional de El Oro, ob.cit; Reglamento Municipal de Panteones de Fresnillo, recuperado de: http://ordenjuridico.gob.mx/ Estatal/ZACATECAS /Municipios/ Fresnillo/FRESREG04.pdf (Consultado: 2/11/2018).

- Reglamento de Cementerios del Distrito Federal, publicado en el Diario Oficial de la Federación, de 28 de diciembre de 1984, recuperado de: http://www. ordenjuridico.gob.mx/ Documentos/ Estatal/Distrito\%20Federal/ wo27567. pdf (Consultado: 2/11/2018).

- Reglamento de Cementerios Municipales para el Municipio de Bolaños, Jalisco, recuperado de:http://www.inafed.gob. $\mathrm{mx} /$ work/paginas_municipales/14019_ bolanos / Articulo\%208/II.\%20 In formacion $\% 20$ sobre $\% 20$ el $\% 20$ marco $\% 20$ juridico $\% 20$ aplicable $\% 20$ al $\% 20 y \% 20$ por $\% 20$ el $\% 20$ sujeto $\% 20$ o bligado / d / r e g la m en to s \% 20 municipales/REGLAMENT0\%20DE $\% 20$ CEMENTERIOS\%20MUNICIPALES.pdf (Consultado: 2/11/2018).

- Reglamento de régimen interior de los Cementerios Municipales de Güeñes, recuperado de: http://www. guenes.eus /es-ES/Ayuntamiento / Ordenanzas-Reglamentos/Ordenanzas Reglamentos / 02 -cementerios.pdf (Consultado 2/11/2018).

- Ordenanza Reguladora de los Requisitos para la Prestación de Servicios Públicos Funerarios en el municipio de Guadalajara. BOP Guadalajara 1998-01-17.

- Argentina.

- Constitución Nacional de la República Argentina, aprobada por la Convención Nacional Constituyente de la ciudad 
de Santa Fe, el 22 de agosto de 1994, recuperado de: http://www.georgetown. edu/pdba/Constitutions / Argentina / argen94.html (Consultado: 12/6/2018).

- Ordenanza de la Municipalidad de la ciudad de San Miguel de Tucumán No. 3306/03.

- Ordenanza de la Municipalidad de la ciudad de Santiago del Estero No. 838 de 23 de junio de 1983, "Código de Cementerios".

- Ordenanza de la Municipalidad de la ciudad Lomas de Zamora No. 545 de 27 de junio de 1915, modificada por las Ordenanzas No. 1419 de 7 de enero de 1949, No. 1546 de 19 de septiembre de 1952, No. 4200 de 14 de septiembre de 1984, No. 7045 de 14 de diciembre de 1993, No. 9896 de 28 de junio de 2001, y No. 11380 de 6 de diciembre de 2006.

- Chile.

- Código Civil de Chile, actualizado al año 2000, vigente desde el 1 de enero de 1857.

- Decreto con Fuerza de Ley No. 725 de 11 de diciembre de 1967, vigente desde el 31 de enero de 1968, modificado hasta el 13 de septiembre de 2011 mediante Ley 20533 de la propia fecha, recuperado de http://
www.leychile.cl/N?i=5595\&f=2011-0913\&p= (Consultado: 11/12/2018).

- Decreto No. 357 de 15 de mayo de 1970, vigente desde el 18 de junio de 1970 , modificado hasta el 8 de febrero de 2006 mediante Decreto 4 de la propia fecha, recuperado de http://www.leychile. $\mathrm{cl} / \mathrm{N}$ ? $\mathrm{i}=12643 \& \mathrm{f}=2006-02-08 \& \mathrm{p}=$ (Consultado: 11/12/2018).

- Resolución No. 6l-G.G./2017 de la municipalidad de Valparaíso, de 25 de abril de 2017 "Reglamento de los Cementerios No 1, 2 y 3 de Valparaíso administrados por la Corporación Municipal de Valparaíso para el Desarrollo Social".

- Código Sanitario de Chile...ob.cit.

- Reglamento General de Cementerios... ob.cit.

- Ordenanza No. 003 de Funcionamiento del Parque Cementerio General de Temuco de 28 de julio de 2010.

- Decreto Exento No. 61 Reglamento No. 12 de Cementerio de la I. Municipalidad de Nueva Imperial de 18 de diciembre de 2012. 